\title{
Wave effects on coastal upwelling and water level
}

\author{
Lichuan Wua ${ }^{\mathrm{a}, \mathrm{b}, *}$, Joanna Staneva $^{\mathrm{c}}, \varnothing_{\text {yvind Breivik }}^{\mathrm{d}, \mathrm{e}}$, Anna Rutgersson ${ }^{\mathrm{a}, \mathrm{f}}$, A. J. \\ George Nurser $^{\mathrm{g}}$, Emanuela Clementi ${ }^{\mathrm{h}}$, Gurvan Madec ${ }^{\mathrm{i}}$ \\ ${ }^{a}$ Department of Earth Sciences, Uppsala University, Uppsala, Sweden \\ ${ }^{b}$ Swedish Meteorological and Hydrological Institute, Norrköping, Sweden \\ ${ }^{c}$ Institute of Coastal Research, Helmholtz-Zentrum Geesthacht, Geesthacht, Germany \\ ${ }^{d}$ Norwegian Meteorological Institute, Norway \\ ${ }^{e}$ Geophysical Institute, University of Bergen, Norway \\ ${ }^{f}$ Centre for Natural Disaster Science, Uppsala University, Uppsala, Sweden \\ ${ }^{g}$ National Oceanography Centre, Southampton, United Kingdom \\ ${ }^{h}$ EuroMediterranean Center on Climate Change (CMCC), Bologna, Italy \\ ${ }^{i} L^{\prime}$ Ocean-IPSL, CNRS, France
}

\begin{abstract}
Traditional atmosphere, ocean and wave models are run independently of each other. This means that the energy and momentum fluxes do not fully account for the impact of the oceanic wave field at the air-sea interface. In this study, the Stokes drift impact on mass and tracer advection, the Stokes-Coriolis forcing and, the sea-state-dependent momentum and energy fluxes are introduced into an ocean circulation model and tested for a domain covering the Baltic Sea and the North Sea. Sensitivity experiments are designed to investigate the influence on the simulation of storms and Baltic Sea upwelling. Inclusion of wave effects improves the model performance compared with the stand-alone circulation model in terms of sea level height, temperature and circulation. The direct sea-state-dependent momentum and turbulent kinetic energy fluxes prove to be of higher importance than the Stokes drift related effects investigated in this study (i.e., Stokes-Coriolis forcing and Stokes drift advection on tracers and on mass). The latter affects the mass and tracer advection but largely balances the influence of the Stokes-Coriolis forcing. The upwelling frequency changes by more than $10 \%$ along the Swedish coast when wave effects are included. In general, the strong (weak) upwelling probability is reduced (increased) when adding the wave effects. From the results, we
\end{abstract}

\footnotetext{
* Corresponding author

Email address: lichuan.wu@geo.uu.se; wulichuano704@gmail.com (Lichuan Wu)
} 
conclude that inclusion of wave effects can be important for regional, high-resolution ocean models even on short time scales, suggesting that they should be introduced in operational ocean circulation models. However, care should be taken when introducing the Stokes-Coriolis forcing as it should be balanced by the Stokes drift in mass and tracer advection.

Keywords: Surface waves; Stokes-Coriolis forcing; Stokes advection; Coupling;

Sea-state-dependent fluxes

\section{Introduction}

Waves play a buffering role in air-sea interaction processes and affect the air-sea interface directly on scales up to the depth of the mixed layer (i.e., Axell, 2002; Sullivan et al. 2007; Sullivan and McWilliams, 2010; McWilliams et al., 2012; Li et al., 2017)

5 and indirectly even deeper (e.g., Breivik et al., 2015). However, the impact of surface waves on air-sea interaction processes is often ignored since the temporal and spatial scales of surface waves are much smaller than the atmospheric and oceanic dynamic scales (Hasselmann, 1991).

The flow of the oceanic and atmospheric boundary layers is affected by surface waves, as has been observed in the open ocean (e.g. Högström et al. 2015) and laboratory experiments (e.g. Buckley and Veron, 2016) and has been simulated with numerical models (e.g. Sullivan and McWilliams, 2010). Surface waves affect the momentum flux/wind stress (Wu et al., 2016, 2017; Staneva et al., 2017), heat fluxes (Veron et al., 2008) and mixed layer turbulence levels (Craig and Banner, 1994; Sullivan et al., 2004;

15 Sullivan and McWilliams, 2010, Cavaleri et al. 2018). Traditionally, atmospheric and oceanic models have been run separately without a wave model to represent the boundary between the two media. This can cause biases in the upper ocean due to insufficient (or in some cases too strong, see Breivik et al. 2015) mixing and because the momentum transfer is shifted in time and space compared to how the fluxes would behave in the presence of waves. Recently, several sea-state-dependent momentum flux (i.e., Guan and Xie, 2004, Wu et al., 2016) and turbulence closure parameterizations have been proposed (i.e., McWilliams and Sullivan, 2000; Smyth et al. 2002, Qiao 
et al. 2004, Huang and Qiao, 2010) and improved performance has been reported for global and regional oceanic and coupled ocean-wave-atmosphere model systems (Breivik et al., 2015; Staneva et al., 2017, Wu et al., 2015, 2016). Here we will briefly summarize the various wave-induced and wave-related processes that affect the upper ocean before we explain and motivate which processes we have chosen to model.

\subsection{Stokes drift related processes}

Stokes drift, $\mathbf{u}_{\mathrm{S}}$, is the drift in the wave propagation direction induced by the motion of surface waves, which can be expressed as the mean temporal and spatial difference between the Eulerian, $\mathbf{u}$, and Lagrangian velocities, $\mathbf{u}_{\mathrm{L}}$ (Stokes, 1847),

$$
\mathbf{u}_{\mathrm{S}}=\mathbf{u}_{\mathrm{L}}-\mathbf{u}
$$

Three terms related to the Stokes drift are indicated in the wave-averaged momentum equation, which can be written, loosely following the notation adopted by Suzuki and Fox-Kemper (2016) (see their Eq. 2), as

$$
\frac{D \mathbf{u}}{D t}=-\nabla(\frac{p}{\rho_{\mathrm{w}}}+\underbrace{\frac{1}{2}\left|\mathbf{u}_{\mathrm{L}}\right|^{2}-\frac{1}{2}|\mathbf{u}|^{2}}_{\text {Press corr }})+\mathbf{u} \times f \hat{\mathbf{z}}+\underbrace{\mathbf{u}_{\mathrm{S}} \times f \hat{\mathbf{z}}}_{\mathrm{CSF}}+\mathbf{D}^{\mathrm{u}}-g \hat{\mathbf{z}}-\underbrace{(\nabla \times \mathbf{u}) \times \mathbf{u}_{\mathrm{S}}}_{\text {Vortex force }} .
$$

Here $p$ the pressure, $\hat{\mathbf{z}}$ is the upward unit vector, $\mathbf{D}^{\mathrm{u}}$ represents parameterizations of sub-grid scale processes, and $\frac{D \mathrm{u}}{D t}=\frac{\partial \mathrm{u}}{\partial t}+(\mathrm{u} \cdot \nabla) \mathrm{u}$ is the material or total derivative. The wave effects manifest themselves as the Coriolis-Stokes force (CSF) (Hasselmann, 1970), the vortex force and a Stokes-corrected pressure (McWilliams and Restrepo, 1999).

Langmuir turbulence (LT) is believed to influence the whole ocean surface boundary layer (e.g., Sullivan et al., 2007; McWilliams et al., 2012; Belcher et al., 2012). Large-eddy simulations show that the LT homogenize the currents and leads to a negative bulk eddy viscosity near the surface (Sullivan et al. 2007) and suggests that LT has a nonlocal character. Several oceanic turbulence closure schemes incorporating LT have been proposed (e.g., McWilliams and Sullivan, 2000, Smyth et al., 2002, Harcourt and D'Asaro, 2008) and implemented into ocean models (Fan and Griffies, 2014; 
Li et al., 2016). For $K$-profile parameterizations (KPP, see Large et al. 1994), a whole range of suggested modifications exist [see e.g., McWilliams and Sullivan 2000, Smyth et al. 2002; Harcourt and D'Asaro 2008; Takaya et al. 2010; Van Roekel et al. 2012],

50 whereas Harcourt (2013) and Harcourt (2015) has introduced LT in a two-equation second-order turbulence closure schemes in the vein of Mellor and Yamada (1982).

\subsection{The wave-induced energy flux and turbulence}

The wave-induced turbulent kinetic energy (TKE) flux is usually parameterised in terms of a friction velocity (Craig and Banner, 1994). The parameterization works relatively well for fully developed sea state but performs poorly under growing and decaying sea states (Kantha and Clayson, 2004, He and Chen, 2011; Cai et al., 2017). The impact of the TKE flux is confined to the wave-breaking zone, and decays rapidly with depth (e.g. Terray et al., 1996; Janssen, 2012; Thomson et al. 2016; Esters et al., 2018). The importance of wave-generated turbulence near the sea surface was also demonstrated by Davies et al. (2000), for the bottom layer by Jones and Davies (1998) and for wave-induced turbulence by Babanin (2006), Huang and Qiao (2010), Babanin et al. (2010) and Babanin and Chalikov (2012).

\subsection{Stress balance at the air-sea interface}

The air-side wind stress is usually estimated from Monin-Obukhov Similarity Theory (MOST), e.g., COARE (Edson et al., 2013). When a wave model is available, the ocean surface roughness length can be estimated from the wave spectrum (Janssen, 1989). Previous studies (Drennan et al., 1999, Rutgersson et al., 2001: Högström et al., 2013) have shown that the MOST may be invalid over waves. Some studies have tried to parametrize the total momentum flux over the ocean by two separate terms, i.e., the wave-coherent momentum flux and the residual momentum flux (Högström et al. 2015, Wu et al., 2017).

Traditionally, ocean circulation models assume that the air-side momentum flux (the wind stress $\tau_{\mathrm{a}}$ ) is identical to the momentum flux into the ocean interior, $\tau_{\mathrm{oc}}$. The role of surface waves is then ignored, assuming that surface waves do not take or release any momentum flux to ocean currents. This assumption is only valid when 
surface waves are fully developed (i.e., in equilibrium with the local wind, Pierson and Moskowitz 1964). Mostly this is not the case, as winds are variable in time and space, and waves wax and wane on time scales from minutes to hours. Some of the momentum flux, $\tau_{\text {in }}$ is absorbed by the wave field, and so the net momentum flux to the currents in the ocean is (ECMWF, 2017; Staneva et al., 2017)

$$
\tau_{\mathrm{oc}}=\tau_{\mathrm{a}}-\tau_{\mathrm{in}}-\tau_{\mathrm{ds}}
$$

where $\tau_{\mathrm{a}}-\boldsymbol{\tau}_{\text {in }}$ is the part of the wind stress $\tau_{\mathrm{a}}$ that directly accelerates the ocean, and $\tau_{\mathrm{ds}}$ is the momentum flux from the wave field to mean currents when the waves break. Here, $\tau_{\mathrm{ds}}$ represents momentum loss from the wave field (Janssen, 2012).

The main effects of waves on the mean flow are due to radiation stress and Stokes drift, although interaction with turbulence and bottom stress can also be important (e.g., Wang and Shen, 2011). Surface waves can affect the water level and thus the storm surge through changes to the stress and upper ocean mixing and circulation (i.e., Dean and Dalrymple, 1991, Mastenbroek et al., 1993). Dietrich et al. (2011) showed that adding the radiation stress improves the model simulation of storm surges driven by hurricanes in the Gulf of Mexico, and a study of two wind storms in the North Sea (Staneva et al. 2017) found that adding the CSF and sea-state-dependent momentum and energy fluxes gave better agreement with measurements compared with a control experiment without wave effects.

Previous studies (Breivik et al., 2015; Alari et al., 2016; Staneva et al., 2017) have implemented the CSF and sea-state-dependent momentum and energy fluxes into the Nucleus of European Modelling of the Ocean (NEMO) model (Madec et al., 2015). Here, we add the Stokes drift in the mass and tracer advection equations with a layeraveraged Stokes drift profile (Breivik et al., 2016, Li et al., 2017). We will not attempt to investigate the impact of Langmuir turbulence in this study and will focus on the direct impact of the Stokes drift through the two competing processes of the CSF and material Stokes drift transport. This allows us to compare our results against these earlier studies which have left out the material Stokes drift transport. The wave-effects in the momentum equation (2) used in this study will be restricted to the Stokes-Coriolis 
force. In the horizontal momentum equation, the vortex force and pressure correction are of the order of the Rossby number relative to the Stokes-Coriolis force and so are expected to be small on the spatial and temporal scales under consideration (see Section 22. We neglect the wave-effect in the vertical (hydrostatic) momentum equation stated in Suzuki and Fox-Kemper (2016) in this study for simplicity. The rest of the paper is structured as follows: the surface wave effects under consideration are presented in Section 2. The experiment design as well as the measurements used in this study are discussed in Section 3 and the simulation results are presented in Section 4 A discussion of the most important findings is found in Section 5 and conclusions are summarized in Section 6

\section{Wave effects introduced in the NEMO model}

Four wave-related processes are investigated in the present study, (i) CSF, (ii) the advection of tracer and mass by the Stokes drift, (iii) sea-state-dependent momentum flux, and (iv) the flux of turbulent kinetic energy from breaking waves. In this study, we are (a) focusing on the terms important on the larger scale and (b) not attempting to investigate the detailed implications of Langmuir turbulence. We ignore the pressure correction and vortex-force in the horizontal components of the momentum equation (2) as they are of the order of the Rossby number. Although the model resolution can become as fine as $3.7 \mathrm{~km}$, we are not really resolving processes on that scale, and certainly not the submesoscale $(1-2 \mathrm{~km})$ fronts where the Stokes-shear force has peen found to be important (Suzuki and Fox-Kemper, 2016; McWilliams and Fox-

125 Kemper, 2013, McWilliams et al. 2015). The Rossby number is generally small in our model simulations so these terms may reasonably be neglected. Here we describe the equations governing the evolution of NEMO as modified by the wave effects that we include.

\subsection{Impact of Stokes drift on momentum and tracer and mass advection}

The Stokes drift impact on mean currents in large scale Eulerian ocean models is through the CSF and LT. The CSF is a forcing induced by the interaction between the 
Coriolis effect and the wave-induced Stokes drift (Hasselmann, 1970). The CSF can modify the vertical distribution of momentum in the turbulent Ekman layer (Polton, 2009). Previous studies (Breivik et al., 2015, Alari et al., 2016; Staneva et al., 2017) ${ }_{135}$ implemented the CSF in the NEMO ocean model but left out the additional effects of the Stokes drift on (i) the mass transport through the divergence of the sea-surface height, $\eta$, and (ii) the advection of tracers (e.g. McWilliams and Sullivan, 2000). After including the CSF (but not the other wave-effects), the wave-averaged momentum equation (2) simplifies to

$$
\frac{D \mathbf{u}}{D t}=-\frac{1}{\rho_{\mathrm{w}}} \nabla p+\mathbf{u} \times f \hat{\mathbf{z}}+\mathbf{u}_{\mathrm{S}} \times f \hat{\mathbf{z}}+\mathbf{D}^{\mathbf{u}} .
$$

The two additional effects (i) and (ii) of the Stokes drift in Eulerian ocean models can be written

$$
\begin{gathered}
\frac{D c}{D t}=-\mathbf{u}_{s} \cdot \nabla c+\mathbf{D}^{c} \\
\frac{\partial p}{\partial z}=-\rho g \\
\nabla \cdot \mathbf{u}=0 \\
\nabla \cdot \mathbf{u}_{\mathbf{s}}=0 \\
\frac{\partial \eta}{\partial t}=-\nabla_{h} \int_{z=-H}^{z=\eta}\left(\mathbf{u}_{h}+\mathbf{u}_{\mathrm{S}}\right) d z .
\end{gathered}
$$

Here, $c$ in the tracer advection equation (5) is a scalar quantity, such as temperature or salinity; and $\mathbf{D}^{\mathrm{c}}$ is the parameterization of sub-grid scale physical processes.

The surface Stokes drift is usually parameterized using wind or friction velocity. Compared with the surface Stokes drift estimated from the full two-dimensional (2D) wave spectrum, the wind or friction velocity-dependent parameterizations overestimate or underestimate the surface Stokes drift under some wind conditions (see Appendix). The shear of the Stokes drift, an important factor when calculating the CSF, can be 
calculated from the wave spectrum following Kenyon (1969). However, it is expensive to estimate the Stokes drift from the 2D wave spectrum as it has to be calculated at every vertical level of interest. Moreover, the full 2D spectrum may not be available. A monochromatic profile of the Stokes drift has commonly been used to estimate the Stokes drift profile in models. However, the shear of the monochromatic Stokes drift profile is much weaker than from a broad spectrum since the Stokes drift from short waves decays quickly with depth (Breivik et al., 2014). In order to estimate the Stokes drift more accurately, Breivik et al. (2016) proposed a more exact parameterization of the Stokes drift profile under a one-dimensional Phillips-type spectrum (Phillips, 1958) which has a better representation of the Stokes drift shear than the monochromatic profile (Breivik et al., 2016, Li et al., 2017). The Stokes drift profile is then approximated by,

$$
u_{\mathrm{S}}(z)=u_{\mathrm{S}_{0}}\left[e^{-2 \bar{k}|z|}-\beta \sqrt{2 \pi \bar{k}|z|} \operatorname{erfc}(\sqrt{2 \bar{k}|z|})\right],
$$

where $\bar{k}$ is the inverse depth scale. The expression for $\bar{k}$ can be found in the study by Breivik et al. (2016). The parameter $\beta$ is treated as constant equal to 1 , following Breivik et al. (2016). The new Stokes drift profile has a better agreement with the profile calculated from a full wave spectrum compared than the monochromatic profile. As ocean models represent vertical and horizontal averages over a grid box, it is necessary to compute the layer-averaged Stokes drift profile, following Li et al. (2017), Appendix A:

$$
u_{\mathrm{S}}\left(z_{i}\right)=\frac{\int_{z_{i, \mathrm{~b}}}^{0} u_{\mathrm{S}}\left(z^{\prime}\right) d z^{\prime}-\int_{z_{i, \mathrm{t}}}^{0} u_{\mathrm{S}}\left(z^{\prime}\right) d z^{\prime}}{z_{i, \mathrm{t}}-z_{i, \mathrm{~b}}} .
$$

Here $z_{i, b}$ and $z_{i, t}$ are the of the bottom and top of the $i$-th vertical level.

\subsection{The sea-state dependent momentum flux}

At the air-sea interface, the sea state modifies both the air-side momentum flux $\tau_{\mathrm{a}}$ (by changing sea surface roughness and hence the drag coefficient) and the water-side momentum flux $\tau_{\text {oc }}$ (through the various amount of breaking waves under wave growth and decay). These two effects are described in the following subsections. 


\subsubsection{Water-side momentum flux}

The momentum flux from the surface wave field to the ocean interior can be expressed in terms of the spectral source terms as

$$
\boldsymbol{\tau}_{\mathrm{oc}}=\boldsymbol{\tau}_{\mathrm{a}}-\rho_{\mathrm{w}} g \int_{0}^{2 \pi} \int_{0}^{\infty} \frac{\mathbf{k}}{\omega}\left(S_{\mathrm{in}}+S_{\mathrm{ds}}\right) d \omega d \theta,
$$

where $S_{\mathrm{ds}}$ is the dissipation due to surface wave breaking and depth-induced breaking, and $S_{\text {in }}$ represents the wind input source term.

Fig. 19 illustrates the relationship between the wave age and the normalized waterside momentum flux, $\left|\boldsymbol{\tau}_{\mathrm{oc}}\right| /\left|\boldsymbol{\tau}_{\mathrm{a}}\right|$. The wind speed within the blue domain shown in Fig. 2 is shown as colored dots. The bin average with standard deviation is also shown in the figure as circles and bars, respectively. The normalized momentum flux ranges from about 0.85 to more than 1.8 , which means that using the air-side momentum flux as a proxy will overestimate (underestimate) the water-side momentum flux by up to $20 \%$ (45\%), respectively. In general, the ratio $\left|\boldsymbol{\tau}_{\mathrm{oc}}\right| /\left|\boldsymbol{\tau}_{\mathrm{a}}\right|$ decreases with increasing $u^{*} / C_{\mathrm{p}}$, where $u^{*}$ is the air-side friction velocity and $C_{\mathrm{p}}$ is the phase speed at the peak of the spectrum. Note that the standard deviation is larger for high values of $u^{*} / C_{\mathrm{p}}$ as there are fewer data points in this regime. Higher values of $\left|\tau_{\text {oc }}\right| /\left|\tau_{\text {a }}\right|$ occur mainly under low wind conditions.

\subsubsection{Air-side momentum flux}

The air-side momentum flux (wind stress) is usually calculated using the bulk formulae, i.e., $\tau_{\mathrm{a}}=\rho_{\mathrm{a}} C_{\mathrm{D}} U_{10}^{2}$, where $C_{\mathrm{D}}$ is the drag coefficient. Following the MOST, the drag coefficient under neutral atmospheric conditions can be expressed as

$$
C_{\mathrm{D}}=\frac{\kappa^{2}}{\ln ^{2}\left(z_{10} / z_{0}\right)},
$$

where $\kappa$ is von Kármán's constant, $z_{10}=10 \mathrm{~m}$ and $z_{0}$ is the air-side surface roughness

length. The surface roughness length varies with sea state. The Charnock relationship (Charnock, 1955) is traditionally used to calculate the sea surface roughness length in 
atmospheric models,

$$
z_{0}=\alpha \frac{u^{* 2}}{g},
$$

where $\alpha$ is the Charnock coefficient. Here $\alpha$ is usually treated as a constant $(0.018$ is a common assumption, see Hersbach 2011). However, experiments show that it varies, usually in the range from 0.015 to 0.035 (Powell et al. 2003). The reason is that the sea surface roughness varies not just with wind speed but quite strongly with sea state (Janssen, 1989, 1991). Thus, many studies have parameterised the Charnock coefficient as a function of sea state, such as wave age (e.g. Guan and Xie, 2004). In the coupled ECWAM model (ECMWF, 2017), the Charnock coefficient is parameterised according to quasi-linear theory as a function of the air-side momentum flux that goes into the wave field,

$$
\alpha=\frac{\hat{\alpha}}{\left(1-\tau_{\text {in }} / \tau_{\mathrm{a}}\right)^{1 / 2}}
$$

where $\hat{\alpha}=0.006$, and the wave-induced stress is expressed as (Janssen, 1991),

$$
\boldsymbol{\tau}_{\text {in }}=\rho_{\mathrm{w}} g \int_{0}^{2 \pi} \int_{0}^{\infty} \frac{\mathbf{k}}{\omega} S_{\text {in }} d \omega d \theta
$$

where $\rho_{\mathrm{w}}$ is the water density, $\omega$ the angular frequency, $\theta$ the wave direction, and $S_{\mathrm{in}}$ is the wind input source term. The air-side stress can now be found by iteratively by calculating the roughness length (14) from the modified Charnock parameter 15 . See Janssen (2004), pp 122-124 for further details on the coupling of ECWAM to the atmospheric model. In our runs the wave model is uncoupled from the atmospheric model, therefore no feedback to the atmospheric boundary layer takes place, but the airside stress $\tau_{\text {a }}$ is calculated using the sea-state dependent roughness length following Eqs. [13]-(16).

An example of the relation between the wave age and $\alpha$ is shown in Fig. 17. The hourly output data from the German Weather Service (Deutscher Wetterdienst, DWD) forcing during December 7th, 2015 in the blue box domain shown in Fig. 2 are indicated as dots (color represents wind speed, $U_{10}$ ). Generally, $\alpha$ increases with increasing inverse wave age $\left(u^{*} / C_{\mathrm{p}}\right)$ as the sea surface grows rougher when the sea state becomes 
younger. However, the $\alpha$ has significant scatter under the same wave age caused by differences in wave steepness (the standard deviation and the bin average of $\alpha$ are shown as circles and bars in Fig. 1p). Thus, parameterizations based on bulk estimates will give the same value even if the wave spectra differ significantly. Some studies (e.g., Edson et al. 2013) show that the Charnock coefficient asymptotes to 0.03 at high wind speed. However, $\alpha$ from the WAM model is larger which may be due to that the sea spray influences are not included when calculating $\alpha$ in the WAM model.

\subsection{Sea-state-dependent energy flux}

The TKE flux is ejected into ocean currents due to breaking waves (Terray et al., 1996. Drennan et al., 1996; Sutherland and Melville, 2015). Craig and Banner (1994) suggests that the TKE flux can be parameterized using the air-side friction velocity as $m \rho_{\mathrm{a}} u^{* 3}$. If it is assumed that the water side is in balance with the air side (waves in equilibrium with the local wind), the coefficient $m$ is usually treated as constant with a value of about 3.5. Likewise, the water-side friction velocity, $u_{*}$, can be used, in which case the flux is written as $\alpha_{C B} \rho_{\mathrm{w}} u_{*}^{3}$. Since the momentum flux across the surface is continuous, i.e., $\rho_{\mathrm{a}} u^{* 2}=\rho_{\mathrm{w}} u_{*}^{2}$, and it is clear that $\alpha_{\mathrm{CB}}=\sqrt{\left(\rho_{\mathrm{w}} / \rho_{\mathrm{a}}\right)} m \approx 100$ if assuming $m=3.5$ (Craig and Banner, 1994). Studies have shown that the coefficient ${ }_{1} \alpha_{\mathrm{CB}}$ depends on the sea state (Terray et al., 1996; Feddersen et al., 2007, Jones and Monismith, 2008, Gerbi et al. 2009, Fan and Yu, 2017) and is in the range $\approx 70$ to over 200. The coefficient $\alpha_{\mathrm{CB}}$ can be calculated from the spectral source terms in a wave model (Janssen, 2012, Breivik et al., 2015),

$$
\Phi_{\mathrm{oc}}=-\rho_{\mathrm{w}} g \int_{0}^{2 \pi} \int_{0}^{\infty} S_{\mathrm{ds}} d \omega d \theta=-\alpha_{\mathrm{CB}} \rho_{\mathrm{w}} u_{*}^{3}
$$

The variability of $\alpha_{\mathrm{CB}}$ for the North Sea and the Baltic Sea study areas has been discussed by Staneva et al. (2017) and Alari et al. (2016).

\section{Experiments and data}

\subsection{Model setup}

NEMO is a state-of-the-art framework of ocean-related model components. The OPA (physical core engine) and LIM3 (sea-ice dynamics and thermodynamics pack- 
age) packages are used in this study to investigate wave effects on ocean circulation and hydrography in a regional high-resolution model domain. The details of the NEMO model are described by Madec et al. (2015) and the details of the North Sea-Baltic Sea set-up are documented by Staneva et al. (2017). The domain used in this study is shown in Fig. 2, which covers the Baltic Sea and North Sea. The horizontal resolution of the model is 2 nautical miles (about $3.7 \mathrm{~km}$ ) with $56 z$-levels in the vertical. The vertical layer thickness ranges from $1.5 \mathrm{~m}$ at the surface to around $22 \mathrm{~m}$ in the lowest model levels with 5 levels in the top $10 \mathrm{~m}$. The temperature and salinity climatology by Janssen et al. (1999) is used as initial conditions. At the open boundaries, the Oregon State University (OSU) tidal constituent data base is used (Egbert and Erofeeva, 2002) as well as climatological periodic boundary conditions for the temperature and salinity (Janssen et al., 1999). Hourly atmospheric forcing data (i.e. wind fields, shortwave and long-wave radiation, air temperature, humidity and air pressure) are from DWD's short range regional COSMO-EU atmpospheric forecasts with data assimilation (Baldauf et al., 2011). COSMO-EU has a $7 \mathrm{~km}$ horizontal resolution and 40 vertical levels up to about $24 \mathrm{~km}$ with a domain covering the whole of Europe. COSMO-EU is nested into a global model with $30 \mathrm{~km}$ grid resolution ${ }^{1}$ A $k-\epsilon$ vertical diffusion scheme (prognostic equations for TKE, $k$, and turbulent dissipation, $\epsilon$ ) is used for all simulations through the generalized length scale (GLS) scheme (Umlauf and Burchard, 2003, 2005).

The WAve Model (WAM) (WAMDI, 1988; Komen et al., 1994; Janssen, 2004) is a third-generation spectral wave model. The $2 \mathrm{D}$ wave spectrum evolves according to the energy balance equation,

$$
\frac{d F}{d t}+\frac{\partial}{\partial \phi}(\dot{\phi} F)+\frac{\partial}{\partial \lambda}(\dot{\lambda} F)+\frac{\partial}{\partial \theta}(\dot{\theta} F)=S_{\mathrm{in}}+S_{\mathrm{ds}}+S_{\mathrm{nl}}
$$

where $F$ represents the wave spectral density, $\phi$ denotes the latitude, $\lambda$ represents the longitude, and $S_{\mathrm{nl}}$ is the nonlinear transfer term. The wind input and dissipation terms

${ }^{1}$ For more details please refer to https://www.dwd.de/EN/research/
weatherforecasting/num_modelling/01_num_weather_prediction_modells/
regional_model_cosmo_eu.html


in the WAM model are described in Janssen (1989, 1991). The nonlinear term is based on the parameterization proposed by Hasselmann et al. (1985).

The domain and resolution of the WAM model are the same as for NEMO with 24 directions and 25 frequencies for the wave spectrum (Staneva et al., 2017). The $10 \mathrm{~m}$ wind vectors from DWD's short range forecasts are used to force WAM. The required boundary information for the wave model at the open boundaries of the North Sea is taken from the hourly output of the regional wave model EWAM (Europe WAM), which is run twice a day in operational wave forecast routine at DWD. Hourly fields of surface Stokes drift, significant wave height and mean frequency yield Stokes drift profiles while fluxes of momentum and TKE are used to force NEMO and to increase mixing under breaking waves (shown in Section 2).

\subsection{Experiments}

Four experiments were devised to investigate the wave impact on NEMO (see Table 11. The CTL is the stand-alone NEMO run without explicit wave information. The bulk algorithm developed by Large and Yeager (2004, 2009) is used to calculate the surface fluxes. The normalized energy flux parameter from breaking waves, $\alpha_{\mathrm{CB}}$, is treated as 100 in CTL, STCOR and STFUL (Craig and Banner, 1994). The CSF is introduced in STCOR (as expressed in Eq. 2) but no mass or tracer advection by the Stokes drift. In the STFUL experiment, the Stokes drift is introduced in the mass and tracer advection (equations 9 and 5 in addition to the CSF. All wave processes discussed in Section 2 are implemented in experiment FULL.

The default model (CTL) was used to simulate the period 2014-01-01 to 2015-12-

31. To investigate the wave effects, the following periods were run:

- Storm period simulation (2015-10-31 to 2015-11-30):

The wave effects were switched on from the restart file of the CTL experiment at time 2015-10-31 00:00. The three experiments, i.e, STCOR, STFUL and FULL, are here used to investigate wave effects under storm conditions. During this time period, there are a few low pressure systems passing through the North Sea and the Baltic Sea. Fig. 3(a) and (b) shows the time series of the wind speed and significant wave height at the FINO1 station. The maximum wind speed 
exceeds $20 \mathrm{~m} \mathrm{~s}^{-1}$ while the significant wave height reaches $7 \mathrm{~m}$. During this time period, the inverse wave age $u^{*} / C_{\mathrm{p}}$ is between 0 and 0.1 . The larger value of $u^{*} / C_{\mathrm{p}}$ is mainly in the low wind conditions (Fig. 3(c)). The larger value of $\alpha_{C B}$ and $u_{\mathrm{s}_{0}}$ corresponds to the young waves and high wind conditions (Fig. 3 (d) and (f)). For the normalized wind stress, $\tau_{o c} / \tau_{a}$, the highest values appear for the oldest waves (lowest inverse wave age) and conditions with sudden wind changes (Fig. 3(e)).

- Seasonal simulation (2015-01-01 to 2015-12-31):

The wave effects were switched on at 2015-01-01 00:00 for the seasonal simulations. The three experiments, i.e., STCOR, STFUL and FULL, and the control simulation (CTL) during year 2015 were used to analyze the seasonal impact of waves on circulation and the Baltic Sea upwelling. The seasonal mean fields of $U_{10}$, significant wave height and swell height are shown in Fig. 4. During months JFD (January, February, and December), the mean wind speed in the North Sea is higher than $12 \mathrm{~m} \mathrm{~s}^{-1}$ and less than $10 \mathrm{~m} \mathrm{~s}^{-1}$ in the Baltic Sea. The mean wind direction is from southwest to south in the North and Baltic Seas. The significant wave height $\left(H_{\mathrm{s}}\right)$ decreases from the north (more than $3 \mathrm{~m}$ ) to the south (less than $2 \mathrm{~m}$ ) in the North Sea. This may be due to swell propagating from the Norwegian Sea to the North Sea (Fig. 4f shows the swell significant wave height). The swell significant wave height, $H_{\text {swell }}$, is higher than $1.6 \mathrm{~m}$ in the north part of the North Sea, and less than $0.8 \mathrm{~m}$ in the Baltic Sea. In MAM (March, April and May), the mean wind speed is less than $9 \mathrm{~m} \mathrm{~s}^{-1}$, and the direction is from southwest both in the North and Baltic Sea. The mean $H_{\mathrm{s}}$ is less than 1.8 (1.4) $\mathrm{m}$ in the North Sea (Baltic Sea). In JJA (June, July and August), the mean direction is from the northwest and the wind speed is reduced to less than $7 \mathrm{~m} \mathrm{~s}^{-1}$. The $H_{\text {swell }}$ in the Baltic Sea is less than $0.7 \mathrm{~m}$. In SON (September, October and November), the mean wind is from the southwest and the wave height for both swell and total wave height is larger than in JJA. 


\subsection{Data}

The following measurements were used to assess the model performance in this study.

\section{- MARNET}

The Marine Environmental Monitoring Network in the North Sea and Baltic Sea (MARNET) comprises twelve automated measuring stations. It is operated by the Federal Maritime and Hydrographic Agency of Germany (BSH). The station locations are shown as red dots in Fig. 2 Their locations are listed in Table 2. The data include water temperature, salinity, oxygen saturation, and meteorological data. For details of the stations and data refer to http://www.bsh.de/ en/Marine_data/Observations/MARNET_monitoring_network/ index.jsp

\section{- $\mathrm{ADCP}$}

Measurements from Acoustic Doppler Current Profilers (ADCP) at FINO3 were used to compare with the current velocities in NEMO. The type of ADCP used (Nortek Acoustic Wave and Current Meter (AWAC)) is designed to measure both current profiles and wave parameters.

- SMHI dataset

Hourly sea level measurements from the dataset of the Swedish Meteorological and Hydrological Institute (SMHI) were also used. The sea level data sites are marked as blue dots in Fig. 2. Their locations are listed in Table 2. For details see https://www.smhi.se/en/services/open-data/oceanograph-c-observations-1. 33356 .

\section{Results}

\subsection{Extreme conditions}

Fig. 5 shows the sea level anomalies (SLA) at station Furuogrund during the storm simulation period. In general, the CTL experiment reproduces the SLA pattern well. During the storms, CTL underestimates the SLA by up to $30 \mathrm{~cm}$ at this station. Adding 
the CSF influence (STCOR) lowers the SLA (increases the difference with observations FINO3. Adding the CSF does not have a systematic impact on the simulated currents. For example, adding the CSF (STCOR, Fig. 7f) increases the current velocity during the high-velocity periods (the warm colour period) for days 317-319, but decreases 
slightly the currents at day 317.3 and 318 . In general, adding both CSF and the Stokes advection (STFUL) reduces the impact of the CSF. However, the impact of the Stokes drift on the mass and tracer advection does not cancel the influence from the CSF (comparing the simulation results from CTL and STFUL). Adding all the wave effects (FULL) generally leads to better agreement with the measurements compared with the experiments STCOR and STFUL.

The net heat flux and the mixed layer depth at 01:00 UTC, day 318 (November 14), is shown in Figs. 8 and 9 . The spatial patterns seen here are representative of the full storm period. The CSF decreases slightly the heat flux in the centre of the North Sea and the south coast of Sweden (Fig. 8p) whereas when both the CSF and Stokes advection are added (STFUL), the impact is negligible (Fig. 8p). In general, adding all the wave effects (FULL) decreases the heat flux, especially in the North Sea and the southern part of the Baltic sea (by up to $40 \mathrm{~W} \mathrm{~m}^{-2}$, see Fig. $8 \mathrm{~d}$ ). Due to the changes of the heat flux and the momentum flux, adding all the wave influences (FULL) increases the mixed layer depth by more than $10 \mathrm{~m}$ (more than 10\%) in the North Sea (Figs. 405 9 $\mathrm{d})$. The mixed layer depth is defined as the layer where the potential temperature is $0.01{ }^{\circ} \mathrm{C}$ different from the SST. However, the CSF and Stokes advection do not have a significant impact on the mixed layer depth (Figs. 9p and c). The sea-state-dependent momentum flux changes the stress and indirectly changes the heat flux and sea temperature. As stated by Breivik et al. (2015), the ocean model has too vigorous mixing with a constant $\alpha_{C B}$. Compared with the wind stress, sea-state-dependent TKE flux has less impact on SST since its influence is mainly on the surface layer. The influence of the sea-state-dependent momentum flux and TKE flux varies geographically. In general, compared with sea-state-dependent TKE flux, the sea-state-dependent momentum flux has a greater impact on both the heat flux and ocean mixed layer depth, which agrees with the results of Alari et al. (2016).

As shown by Alari et al. (2016), the surface wave influence can extend to the bottom layer, but the main impact is in the mixed layer. Here, the relative mean difference (RMD) of SST and MLD between the control run and FULL are used to show the wave impact with different wave parameters (see Fig. 10). Hourly model fields from within the domain shown as a blue box in Fig. 2 are used. One can see that the wave 
impact on the SST decreases with the mean square slope $\left(\sigma^{2}\right)$ in the range [0 0.01$]$ (from $\approx 2.8 \%$ to $1 \%$ ), then it increases with $\sigma^{2}$ until $\sigma^{2}=0.05$. A similar pattern is found for RMD of MLD (see Fig. 10p). In general, the RMD of MLD and SST increases with the increasing of the value $\left|\tau_{\mathrm{oc}} / \tau_{\mathrm{a}}-1\right|$ (Figs. 10, and $\mathrm{d}$ ). This is due to the ocean-side stress is not equal to the air-side stress which differs the energy input to the ocean compared with the control run. The ratio $H_{\text {swell }} / H_{\text {sea }}$ shows the relative energy of swell waves. It shows that the RMD of SST and MLD decreases with increasing of the relative swell energy (see Fig. 10e and f). The wave impact on the ocean simulation in terms of SST and MLD first increases with inverse wave age $\left(u^{*} / C_{\mathrm{p}}\right)$ and then decreases with inverse wave age. The maximum influence occurs at $u^{*} / C_{\mathrm{p}}=0.06$.

\subsection{Seasonal influence}

The 3-hourly averaged output from the seasonal simulation period is used to investigate the wave effects. Fig. 11] shows the SST discrepancies between the model and measurements for all stations marked with red circles in Fig. 2 The correlation coefficients for the four experiments are all higher than 0.9. There is no significant difference between the experiments STCOR/STFUL and CTL concerning the root mean square error of SST, standard deviation and coefficient at those stations. Adding the sea-state-dependent momentum and energy fluxes improves the model simulation of SST (increases the correlation coefficients and decreases the standard deviation and root mean square errors).

The mean summer SST (JJA) is shown in Fig. 12 1 . In summer, the SST along the Swedish south coast is lower than the zonal average SST in the Baltic Sea. This may be caused by the coastal upwelling. Adding the CSF (STCOR) increases the SST by more than $0.2{ }^{\circ} \mathrm{C}$ in the southern Baltic Sea and in some areas in the western North Sea. In contrast, adding the CSF reduces the SST along the Finnish coast and the south coast of Norway (Fig. 12p). Adding both the CSF and the Stokes advection, STFUL, reduces the influence from the CSF (Fig. 12, ). The SST differences between FULL and CTL show no significant difference (less than $0.05^{\circ} \mathrm{C}$ ). When the seastate-dependent momentum and TKE fluxes are added to STFUL (FULL), the SST 
is reduced by more than $0.6{ }^{\circ} \mathrm{C}$ in the Baltic Sea and $0.3{ }^{\circ} \mathrm{C}$ in the North Sea, away from the coast. However, the FULL experiment increases the SST along the eastern and southern Swedish coast, the east coast of Gotland, and the Finnish south coast in summer (Fig. 12 $\mathrm{d})$.

Fig. 13 shows the mean SST from the CTL experiment in winter (JFD). Adding the CSF increases the SST about $0.3{ }^{\circ} \mathrm{C}$ in the southern and northern parts of the Baltic sea, but decreases the SST by about $0.2{ }^{\circ} \mathrm{C}$ in the middle part of the Baltic Sea (see Fig. 13 p). Similar to the summertime period, adding the Stokes advection reduces the influence of CSF on the SST (Fig. 136). Adding all the wave effects (FULL) increases the SST more than $0.4{ }^{\circ} \mathrm{C}$ in the Baltic Sea. However, adding all the wave effects increases the SST in some areas in the North Sea (e.g., the south part of the North Sea and the southern coast of Norway) and decreases the SST in some areas in the North Sea (see Fig. 13 d).

Comparing the SST from the three wave experiments (STCOR, STFUL, and FULL) with the CTL experiment, we see that as expected the Stokes advection reduces the influence of the CSF. The sea-state-dependent momentum and TKE fluxes dominate over the CSF and the Stokes advection in this study.

\subsection{Coastal Upwelling}

Coastal upwelling is an important phenomenon. Where the wind blows parallel to a coastline, wind-driven horizontal divergence can cause cold, nutrient-rich water to rise to the surface. Upwelling can lead to a drop in the sea surface temperature (SST) of more than $10^{\circ} \mathrm{C}$ in less than two days (Lips and Lips, 2008). The divergence (convergence) of the wind stress is the major factor affecting upwelling (Lehmann and Myrberg, 2008). Upwelling can affect the marine atmospheric boundary layer (Sproson and Sahlée, 2014), $\mathrm{CO}_{2}$ fluxes (Norman et al. 2013) and biological productivity (Lehmann and Myrberg, 2008). The Baltic Sea is a semi-enclosed basin and winds from all directions cause upwelling along one coast or another. Climatological studies have shown that the Baltic Sea has high upwelling frequencies in the summer months (e.g., Lehmann and Myrberg, 2008). The surface wave influence on the upwelling has 
surface waves on the upwelling events which have a surface temperature signal in the Baltic Sea. The method described in Lehmann et al. (2012) was used to detect upwelling events. A north-south SST gradient is usually present in the Baltic Sea. We use the SST difference in every model grid point from the zonal mean to detect upwelling events. Different SST criteria have been used in other studies, such as $1{ }^{\circ} \mathrm{C}$ (Norman et al. 2013). Here, we require that the SST difference be greater than $2.5^{\circ} \mathrm{C}$ within $25 \mathrm{~km}$ from the coast.

With 3-hourly resolution, we record upwelling events in all model grid points within the Baltic Sea. Then the upwelling frequency is estimated as the ratio between the number of upwelling events and the total number of samples in each grid point. The upwelling frequency from the control experiment (CTL) for the months June, July, August and September 2015 is shown in the first column of Fig. 14. In June and July 2015, the most frequent upwelling is found along the Swedish south coast, the east and south coasts of Öland and Gotland islands. The upwelling frequency is generally above $30 \%$, with extremes of $80 \%$ in those areas during June and July 2015. In June 2015, the upwelling frequency exceeds 50\% along the coast of Helsinki. In August 2015, the upwelling frequency along the Swedish south coast is below 40\%. In September 2015, upwelling events are mainly along the east coast of Öland, with frequency in excess of $50 \%$, and along the coast of Gotland with a frequency a little below 30\%. In August and September, the upwelling events in the Gulf of Finland are quite infrequent. One possible reason is that the upwelling events are weak in those two months and cannot be detected using $2.5^{\circ} \mathrm{C}$ temperature difference with zonal mean as the upwelling criterion.

The second to fourth columns of Fig. 14 show the wave impact on the upwelling frequency for the months June, July, August and September 2015. Warm colours indicate that adding the wave effect increases the upwelling frequency and cold colours indicate that it reduces the upwelling frequency. In June, adding the CSF (Fig. 14p) reduces the upwelling frequency (about 3\% and extremes of around 5\%) along the Swedish south coast. In July, it reduces the upwelling frequency by more than 5\% and in extreme cases by about 10\% (Fig. 14f). Adding the CSF increases the upwelling frequency in September along the east coast of Öland. In the Gulf of Bothnia and Finland 
and along the coast of Gotland, STCOR generally increases the upwelling frequency compared with CTL. The maximum frequency difference induced by the CSF occurs in September, at most by about $6 \%$ in the Gotland coast. Adding both the CSF and the Stokes drift advection (STFUL) generally reduces the impact of CSF, but there are some exceptions in the Gulf of Finland and along the south coast of the Gotland. In the Gulf of Finland, adding both the CSF and the Stokes drift impact on the mass and tracer advection has a bigger impact on the upwelling frequency than adding only the CSF. Along the south coast of the Gotland, it even reverses the trend from increasing the upwelling frequency (STCOR) to decreasing it (STFUL). When all the wave effects are added (FULL), a bigger influence on the upwelling frequency is found in June, July and August. In June, the experiment FULL reduces the upwelling frequency along the south Swedish coast by more than $8 \%$. FULL actually increases the upwelling frequency compared with CTL (see Fig. 14h) along the Swedish east coast in July. In September, adding only the CSF has a greater impact on the upwelling frequency than adding both the CSF and Stokes drift tracer advection (STFUL) or adding all wave effects (FULL), see Fig. 14h, o, and p).

In general, adding CSF changes the upwelling frequency significantly in the areas that surface Stokes drift gradient is large, such as the east and south coast of Sweden in June, July and August (see the first column of Fig. 15. The Stokes drift in the Swedish coast is smaller than the areas far away from the coast. It indicates that the CSF-induced upper ocean mixing is smaller in the coastal areas than the others. In most cases (see also Figs. 12, 13, ), the CSF and the Stokes drift material and tracer advection tend to counter each other. The sea-state dependent TKE and momentum fluxes dominate wave-related processes investigated in this study. One can see that the momentum and energy fluxes are reduced in the coastal areas when adding sea-state dependent momentum/TKE flux. This leads to less upwelling and increases the upper ocean mixing in the areas far away from the coast. Thus, they reduce the upwelling frequency (see the second and third columns of Fig. 15. It is worth noting that the sea-state dependent stress increases the stress curl in the areas (the upwelling detected areas, within $25 \mathrm{~km}$ from the coast) where $\tau_{o c} / \tau_{\mathrm{a}}$ changes quickly. This drives the increase in the upwelling frequency along the Swedish east coast in July. It indicates that 
younger waves along the coast than other areas can potentially decrease the upwelling frequency. However, the stress curl induced by the waves can also contribute to the upwelling frequency difference. As the sea state modifies both the spatial distribution of wind stress and the ocean interior through the CSF, the combined effect is hard to predict and may vary over short distances due to topographic features.

The SST difference from the zonal mean temperature $(\Delta T)$ is used as an index to assess the wave impact on the upwelling intensity in the Baltic Sea. Here, we divide upwelling $\left(-4<\Delta T<2.5^{\circ} \mathrm{C}\right)$, intermediate upwelling $\left(-6<\Delta T<-4{ }^{\circ} \mathrm{C}\right)$, and strong upwelling $\left(\Delta T<-6{ }^{\circ} \mathrm{C}\right)$. Fig. 16 shows the normalised distribution of the upwelling events in the months June, July, August and September 2015. More than $60 \%$ of upwelling events are weak in these four months. Comparing with the months (strong) upwelling probability by about $4 \%$ in June, 6\% (2\%) in July, and 5\% (1\%) in August and September. 


\section{Discussion}

As one of the most important wave-related processes, the CSF can modify the ocean Ekman transport and lead to an additional veering of the Ekman profile by about $4-5^{\circ}$ (McWilliams and Restrepo, 1999; Polton et al. 2005; Saetra et al., 2007). The current profile can thus be substantially modified in the whole wind-driven layer as shown by Polton et al. (2005). This is also evident in Fig. 7. However, due to indirect influences from CSF, the CSF impact on the current in the location shown in Fig. 7 are not significant (but there are still some differences). The influence varies with location. The implication is that the impact of Stokes drift on mixing and the Eulerian current via Langmuir turbulence may dominate over this effect. In addition, the Stokes drift may indirectly affect the mixing by modifying the Eulerian shear. This is quite evident in Figs. $12 \mathrm{p}$ and $13 \mathrm{p}$ where we see that the inclusion of the CSF modifies the SST throughout the entire North Sea and the Baltic Sea and not just in the expected upwelling and downwelling areas illustrated in Fig. 14 .

The influence of the Stokes drift varies with location and time. The surface Stokes drift is mainly controlled by the high-frequency part of the wave spectrum. Thus, the directional difference between the wind and the Stokes drift is smaller under growing waves since the local wind waves dominate the Stokes drift. When swell dominates, the Stokes drift contribution by low-frequency waves can be substantial, and their direction will in general not align with the local wind direction which means a simple windspeed parameterization of the Stokes drift will tend to perform poorly. In other words, the wave model may yield a bigger influence under swell conditions where wind and waves are not aligned.

In general, adding the wave effects has a positive impact on the model performance compared with the control experiment. However, the biases between the model results and measurements are still large. The biases may be due to the setup of the NEMO model, the bulk parameterization or the forcing data. In this study, our aim was not to achieve the best fit between data and models but rather to investigate the role of the wave-induced processes on hydrography, circulation and its impact during storm events. In addition, we have not included Langmuir turbulence and bottom stress in- 
duced by wave-current interaction in shallow water (Davies and Lawrence 1995), nor have we considered the possible impact of non-breaking waves put forward by Qiao et al. (2004), Babanin (2006) and Babanin and Haus (2009). Wave effects can affect each other, making wave-current interaction a complex non-linear feedback system. For example, due to the Langmuir turbulence, the turbulent mixing of Eulerian momenfum occurs down both the Eulerian current and the Stokes drift gradient (McWilliams et al., 2014; Harcourt, 2015; Reichl et al., 2016). The down-Stokes gradient mixing may partially cancel the Stokes advection because it introduces a counter-Stokes effect on the Eulerian current which is because that mixing acts to homogenize the combined Lagrangian current. Further studies are needed to disentangle the full impact of these wave-related processes on ocean circulation.

\section{Conclusions}

This study extends the work of Alari et al. (2016) and Staneva et al. (2017) on a regional NEMO model with WAM forcing by also introducing the impact of Stokes drift on the mass and tracer advection. Using the NEMO model with a domain covering the Baltic Sea and North Sea we have investigated the impact of the CSF, Stokes drift on the mass and tracer advection and sea-state-dependent momentum and energy fluxes on ocean circulation on very high resolution. Of those wave-related processes, the sea-state-dependent fluxes dominate the Stokes drift effects. In more detail, the sea-state-dependent momentum flux has a larger influence on the simulation than that from sea-state-dependent TKE flux, which agrees with previous studies (Alari et al. 625 2016; Staneva et al., 2017). Furthermore, we found that overall the Stokes drift advection largely counters the effect of the CSF. The CSF can change the SST by more than $0.2{ }^{\circ} \mathrm{C}$, and the influence varies with location and season. The Stokes drift impact on the mass and tracer advection tends to counter the influence of the CSF on ocean circulation. However, these two effects do not always cancel entirely, as seen for the SST (Figs. 12k and 13k) and the associated coastal upwelling (Figs. 14 and 17). Thus, care must be taken to consistently introduce these wave effects together since their combined effect is much smaller (yet still present) than either on its own. The 
terms neglected in this study (e.g., the Stokes correction to the pressure in the momentum equation and the wavy-hydrostatic effect) will be investigated in further studies. Adding all the wave effects discussed in Section 2 decreases (increases) the mean SST by more than $0.6(0.4){ }^{\circ} \mathrm{C}$ in the Baltic Sea during summer (winter).

Including CSF in NEMO changes the Baltic sea upwelling frequency by more than $10 \%$. The combined impact of the CSF and the Stokes drift impact on mass and tracer advection reduces the upwelling frequency difference to less than $2 \%$ compared with

2014). Also, surface waves are affected by ocean currents through current refraction (Janssen, 2004). These processes can only be investigated with fully coupled systems (Mogensen et al., 2017). 


\section{Acknowledgments}

665 mas (project 2017-00516) and ÅForsk Foundation (project 17-393). ØB, JS and GN acknowledge support from Copernicus CMEMS through the project WaveFlow. ØB also acknowledges support from the Research Council of Norway through the CIRFA (grant no. 237906) and RETROSPECT projects (grant no. 244262). JS also acknowl-

Modeling projects. The authors would like to thank Arno Behrens for providing the boundary values for the wave model and Sebastian Grayek for assistance with NEMO.

\section{Appendix}

The Stokes drift must be parameterised from the local wind when wave information 675 is not available. The magnitude of the surface Stokes drift, i.e., $u_{\mathrm{s}_{0}}$, is usually estimated through a wind-speed dependent parameterization, e.g., $u_{\mathrm{s}_{0}}=0.016\left|U_{10}\right|$ Li and Garrett, 1993, or a stress-dependent parameterization, e.g., $u_{\mathrm{s}_{0}}=0.377\left|\boldsymbol{\tau} / \rho_{\mathrm{w}}\right|^{1 / 2}$ where $|\boldsymbol{\tau}|$ is the surface wind stress (Madec et al., 2015) and $\rho_{\mathrm{w}}$ is the water density. The direction of Stokes drift is then assumed to align with the wind direction. However, those parameterizations are unable to capture the Stokes drift in the presence of swell $\left(C_{\mathrm{p}} /\left(\cos \left(\theta_{\text {wave }}-\theta_{\text {wind }}\right) U_{10}\right)>1.2\right.$, where $C_{\mathrm{p}}$ is the wave peak phase speed $)$, as the direction and magnitude of the Stokes drift can be altered significantly by swell propagating in off-wind directions, say $\left|\theta_{\text {wind }}-\theta_{\text {wave }}\right|>45^{\circ}$.

Fig. 18 shows the relationship between the magnitude of the surface Stokes drift estimated by the WAM model and the mean wind speed $(18 \mathrm{a})$ and friction velocity (18p). The dots represent the output from all grid points within the blue box shown in Fig. 2 The wind forcing of WAM is from a short range forecast by the German Weather Service (DWD) on December 7, 2015. In Fig. 18, the dots represent all model values inside the blue domain shown in Fig. 2 The surface Stokes drift is calculated from the full 2D wave spectrum in WAM. The contribution from the spectral

tail beyond the cut-off frequency to the surface Stokes drift is calculated diagnostically and added to the contribution from the main part of the WAM spectrum (ECMWF, 
2017). The color represents the wave age, i.e., $C_{\mathrm{p}} / U_{10}$. The black lines represent the results from the parameterization $u_{\mathrm{s}_{0}}=0.016 U_{10}$ (Li and Garrett, 1993) (Fig. 189) and $u_{\mathrm{s}_{0}}=0.377\left|\tau / \rho_{\mathrm{w}}\right|^{1 / 2}$ (Madec et al. 2015) (Fig. 18p). There is significant scatter between the results from the parameterizations and that calculated by the $2 \mathrm{D}$ wave spectrum. Especially under low wind conditions, both parameterizations overestimate the surface Stokes drift. The direction of the surface Stokes drift differs from the mean wind direction, especially under high wave age conditions (Fig. 18k). The reason is that swell propagating in a different direction than the local wind contributes to the Stokes drift. Thus, the surface Stokes drift parameterised either from the mean wind speed or from the friction velocity can not properly model the Stokes drift.

\section{References}

Alari, V., Staneva, J., Breivik, Ø., Bidlot, J.R., Mogensen, K., Janssen, P., 2016. Surface wave effects on water temperature in the baltic sea: simulations with the coupled nemo-wam model. Ocean Dynamics 66, 917-930.

Axell, L.B., 2002. Wind-driven internal waves and langmuir circulations in a numerical ocean model of the southern baltic sea. Journal of Geophysical Research: Oceans 107.

Babanin, A., 2006. On a wave-induced turbulence and a wave-mixed upper ocean layer. Geophysical Research Letters 33.

Babanin, A.V., Chalikov, D., 2012. Numerical investigation of turbulence generation in non-breaking potential waves. Journal of Geophysical Research: Oceans 117.

Babanin, A.V., Chalikov, D., Young, I., Savelyev, I., 2010. Numerical and laboratory investigation of breaking of steep two-dimensional waves in deep water. Journal of Fluid Mechanics 644, 433-463.

Babanin, A.V., Haus, B.K., 2009. On the existence of water turbulence induced by nonbreaking surface waves. Journal of Physical Oceanography 39, 2675-2679. 
Baldauf, M., Seifert, A., Förstner, J., Majewski, D., Raschendorfer, M., Reinhardt, T., 2011. Operational convective-scale numerical weather prediction with the cosmo model: Description and sensitivities. Monthly Weather Review 139, 3887-3905.

Belcher, S.E., Grant, A.L.M., Hanley, K.E., Fox-Kemper, B., Van Roekel, L., Sullivan, P.P., Large, W.G., Brown, A., Hines, A., Calvert, D., Rutgersson, A., Pettersson, H., Bidlot, J.R., Janssen, P.A.E.M., Polton, J.A., 2012. A global perspective on Langmuir turbulence in the ocean surface boundary layer. Geophys Res Lett 39, 9. doi:10.1029/2012GL052932.

Breivik, Ø., Bidlot, J.R., Janssen, P.A., 2016. A stokes drift approximation based on the phillips spectrum. Ocean Modelling 100, 49-56.

Breivik, Ø., Janssen, P.A., Bidlot, J.R., 2014. Approximate stokes drift profiles in deep water. Journal of Physical Oceanography 44, 2433-2445.

Breivik, Ø., Mogensen, K., Bidlot, J.R., Balmaseda, M.A., Janssen, P.A., 2015. Surface wave effects in the NEMO ocean model: Forced and coupled experiments. Journal of Geophysical Research: Oceans 120, 2973-2992.

Buckley, M.P., Veron, F., 2016. Structure of the airflow above surface waves. Journal of Physical Oceanography 46, 1377-1397.

Cai, Y., Wen, Y., Wu, L., Zhou, C., Zhang, F., 2017. Impact of wave breaking on upper-ocean turbulence. Journal of Geophysical Research: Oceans 122, 1513-1528.

Cavaleri, L., Abdalla, S., Benetazzo, A., Bertotti, L., Bidlot, J.R., Breivik, Ø., Carniel, S., Jensen, R., Portilla-Yandun, J., Rogers, W., Roland, A., Sanchez-Arcilla, A., Smith, J., Staneva, J., Toledo, Y., van Vledder, G., van der Westhuysen, A., 2018.

a Wave modelling in coastal and inner seas. Prog Oceanogr, 70doi:10.1016/j. pocean.2018.03.010.

Charnock, H., 1955. Wind stress on a water surface. Quarterly Journal of the Royal Meteorological Society 81, 639-640. 
Craig, P.D., Banner, M.L., 1994. Modeling wave-enhanced turbulence in the ocean surface layer. Journal of Physical Oceanography 24, 2546-2559.

Davies, A.M., Kwong, S.C., Flather, R.A., 2000. On determining the role of wind wave turbulence and grid resolution upon computed storm driven currents. Continental Shelf Research 20, 1825-1888.

Davies, A.M., Lawrence, J., 1995. Modeling the effect of wave-current interaction on the three-dimensional wind-driven circulation of the eastern irish sea. Journal of Physical Oceanography 25, 29-45.

Dean, R.G., Dalrymple, R.A., 1991. Water wave mechanics for engineers and scientists. volume 2. world scientific publishing Co Inc.

Dietrich, J., Zijlema, M., Westerink, J., Holthuijsen, L., Dawson, C., Luettich, R.A., Jensen, R., Smith, J., Stelling, G., Stone, G., 2011. Modeling hurricane waves and storm surge using integrally-coupled, scalable computations. Coastal Engineering $58,45-65$.

Drennan, W., Donelan, M., Terray, E., Katsaros, K., 1996. Oceanic turbulence dissipation measurements in swade. Journal of Physical Oceanography 26, 808-815.

Drennan, W.M., Kahma, K.K., Donelan, M.A., 1999. On momentum flux and velocity spectra over waves. Boundary-Layer Meteorology 92, 489-515.

ECMWF, 2017. IFS Documentation CY43r1, Part VII: ECMWF Wave Model. ECMWF Model Documentation. European Centre for Medium-Range Weather Forecasts.

Edson, J.B., Jampana, V., Weller, R.A., Bigorre, S.P., Plueddemann, A.J., Fairall, C.W., Miller, S.D., Mahrt, L., Vickers, D., Hersbach, H., 2013. On the exchange of momentum over the open ocean. Journal of Physical Oceanography 43, 1589-1610.

Egbert, G.D., Erofeeva, S.Y., 2002. Efficient Inverse Modeling of Barotropic Ocean 770 \ Tides. J Atmos Ocean Tech 19, 183-204. doi:10.1175/1520-0426(2002) $019<0183: \mathrm{EIMOBO}>2.0 . \mathrm{CO} ; 2$. 
Esters, L., Breivik, Ø., Landwehr, S., A ten Doeschate, G.S., Christensen, K., Bidlot, J.R., Ward, B., 2018. Turbulence Scaling Comparisons in the Ocean Surface Boundary Layer. J Geophys Res: Oceans, 20doi:10.1002/2017JC013525

Fan, Y., Griffies, S.M., 2014. Impacts of parameterized langmuir turbulence and nonbreaking wave mixing in global climate simulations. Journal of Climate 27, 47524775.

Fan, Y., Yu, Z., 2017. Surface gravity wave effect in turbulent kinetic energy flux across the air-sea interface, in: EGU General Assembly Conference Abstracts, p. 5624.

Feddersen, F., Trowbridge, J.H., Williams III, A., 2007. Vertical structure of dissipation in the nearshore. Journal of Physical Oceanography 37, 1764-1777.

Gerbi, G.P., Trowbridge, J.H., Terray, E.A., Plueddemann, A.J., Kukulka, T., 2009. Observations of turbulence in the ocean surface boundary layer: Energetics and transport. Journal of Physical Oceanography 39, 1077-1096.

Guan, C., Xie, L., 2004. On the linear parameterization of drag coefficient over sea surface. Journal of Physical Oceanography 34, 2847-2851.

Harcourt, R., 2013. A Second-Moment Closure Model of Langmuir Turbulence. J Phys Oceanogr 43, 673-697. doi:10.1175/JPO-D-12-0105.1

Harcourt, R.R., 2015. An improved second-moment closure model of langmuir turbulence. Journal of Physical Oceanography 45, 84-103.

Harcourt, R.R., D'Asaro, E.A., 2008. Large-eddy simulation of Langmuir turbulence in pure wind seas. J Phys Oceanogr 38, 1542-1562.

Hasselmann, K., 1970. Wave-driven inertial oscillations. Geophysical and Astrophysical Fluid Dynamics 1, 463-502.

Hasselmann, K., 1991. Ocean circulation and climate change. Tellus A: Dynamic Meteorology and Oceanography 43, 82-103. 
Hasselmann, S., Hasselmann, K., Allender, J., Barnett, T., 1985. Computations and parameterizations of the nonlinear energy transfer in a gravity-wave specturm. part ii: Parameterizations of the nonlinear energy transfer for application in wave models. Journal of Physical Oceanography 15, 1378-1391.

He, H., Chen, D., 2011. Effects of surface wave breaking on the oceanic boundary layer. Geophysical Research Letters 38.

Hersbach, H., 2011. Sea Surface Roughness and Drag Coefficient as Functions of Neutral Wind Speed 41, 247-251. doi $10.1175 / 2010$ JP04567.1

Högström, U., Rutgersson, A., Sahlée, E., Smedman, A.S., Hristov, T.S., Drennan, W., Kahma, K., 2013. Air-sea interaction features in the baltic sea and at a pacific tradewind site: an inter-comparison study. Boundary-layer meteorology 147, 139-163.

Högström, U., Sahlée, E., Smedman, A.S., Rutgersson, A., Nilsson, E., Kahma, K.K., Drennan, W.M., 2015. Surface stress over the ocean in swell-dominated conditions during moderate winds. Journal of the Atmospheric Sciences 72, 4777-4795.

Huang, C.J., Qiao, F., 2010. Wave-turbulence interaction and its induced mixing in the upper ocean. Journal of Geophysical Research: Oceans 115.

Janssen, F., Schrum, C., Backhaus, J.O., 1999. A climatological data set of temperature and salinity for the baltic sea and the north sea. Deutsche Hydrografische Zeitschrift $51,5$.

Janssen, P., 2004. The interaction of ocean waves and wind. Cambridge University Press, Cambridge, UK.

Janssen, P., 2012. Ocean Wave Effects on the Daily Cycle in SST. J Geophys Res: Oceans 117, 24. doi $10 / \mathrm{mth}$.

Janssen, P.A., 1989. Wave-induced stress and the drag of air flow over sea waves. Journal of Physical Oceanography 19, 745-754.

Janssen, P.A., 1991. Quasi-linear theory of wind-wave generation applied to wave forecasting. Journal of Physical Oceanography 21, 1631-1642. 
Jones, J., Davies, A., 1998. Storm surge computations for the irish sea using a threedimensional numerical model including wave-current interaction. Continental Shelf Research 18, 201-251.

Jones, N.L., Monismith, S.G., 2008. The influence of whitecapping waves on the vertical structure of turbulence in a shallow estuarine embayment. Journal of Physical Oceanography $38,1563-1580$.

Kantha, L.H., Clayson, C.A., 2004. On the effect of surface gravity waves on mixing in the oceanic mixed layer. Ocean Modelling 6, 101-124.

Kenyon, K.E., 1969. Stokes drift for random gravity waves. Journal of Geophysical Research 74, 6991-6994.

Komen, G.J., Cavaleri, L., Donelan, M., Hasselmann, K., Hasselmann, S., Janssen, P.A.E.M., 1994. Dynamics and Modelling of Ocean Waves. Cambridge University Press, Cambridge.

Large, W.G., McWilliams, J.C., Doney, S.C., 1994. Oceanic vertical mixing: A review and a model with a nonlocal boundary layer parameterization. Rev Geophys 32, 363-403. doi:10.1029/94RG01872.

Large, W.G., Yeager, S., 2009. The global climatology of an interannually varying air-sea flux data set. Climate dynamics 33, 341-364.

Large, W.G., Yeager, S.G., 2004. Diurnal to decadal global forcing for ocean and seaice models: the data sets and flux climatologies. National Center for Atmospheric Research Boulder.

Lehmann, A., Myrberg, K., 2008. Upwelling in the baltic seaa review. Journal of Marine Systems 74, S3-S12.

Lehmann, A., Myrberg, K., Höflich, K., 2012. A statistical approach to coastal upwelling in the baltic sea based on the analysis of satellite data for 1990-2009. Oceanologia 54, 369-393. 
McWilliams, J.C., Huckle, E., Liang, J.H., Sullivan, P.P., 2012. The wavy ekman layer: Langmuir circulations, breaking waves, and reynolds stress. Journal of Physical Oceanography 42, 1793-1816.

McWilliams, J.C., Restrepo, J.M., 1999. The Wave-driven Ocean Circulation. J Phys 875

Li, M., Garrett, C., 1993. Cell merging and the jet/downwelling ratio in langmuir circulation. Journal of Marine Research 51, 737-769.

Li, Q., Fox-Kemper, B., Breivik, Ø., Webb, A., 2017. Statistical Models of Global

\ Langmuir Mixing. Ocean Model 113, 95-114. doi:10.1016/j.ocemod. 2017. 03.016

Li, Q., Webb, A., Fox-Kemper, B., Craig, A., Danabasoglu, G., Large, W.G., Vertenstein, M., 2016. Langmuir mixing effects on global climate: WAVEWATCH III in CESM. Ocean Model 103, 145-160. doi:10.1016/j.ocemod.2015.07.020.

Lips, I., Lips, U., 2008. Abiotic factors influencing cyanobacterial bloom development in the gulf of finland (baltic sea). Hydrobiologia 614, 133-140.

Madec, G., et al., 2015. Nemo ocean engine .

Mastenbroek, C., Burgers, G., Janssen, P., 1993. The dynamical coupling of a wave model and a storm surge model through the atmospheric boundary layer. J Phys Oceanogr 23, 1856-1866. doi $10 /$ ccb 4 f9.

McWilliams, J.C., Fox-Kemper, B., 2013. Oceanic wave-balanced surface fronts and filaments. Journal of Fluid Mechanics 730, 464-490.

McWilliams, J.C., Gula, J., Molemaker, M.J., Renault, L., Shchepetkin, A.F., 2015. Filament frontogenesis by boundary layer turbulence. Journal of Physical Oceanography $45,1988-2005$.

McWilliams, J.C., Huckle, E., Liang, J., Sullivan, P.P., 2014. Langmuir turbulence in swell. Journal of Physical Oceanography 44, 870-890.

Oceanogr 29, 2523-2540. doi $10 / d w j 9 t j$. 
McWilliams, J.C., Sullivan, P.P., 2000. Vertical mixing by langmuir circulations. Spill Science \& Technology Bulletin 6, 225-237.

Mellor, G.L., Yamada, T., 1982. Development of a turbulent closure model for geo-

n physical fluid problems. Rev Geophys Space Phys 20, 851-875. doi:10.1029/ RG020i004p00851.

Mogensen, K.S., Magnusson, L., Bidlot, J.R., 2017. Tropical cyclone sensitivity to ocean coupling in the ECMWF coupled model. J Geophys Res: Oceans 122, 43924412. doi $10.1002 / 2017$ JC012753.

Norman, M., Parampil, S.R., Rutgersson, A., Sahlée, E., 2013. Influence of coastal upwelling on the air-sea gas exchange of co2 in a baltic sea basin. Tellus B: Chemical and Physical Meteorology 65, 21831.

Phillips, O.M., 1958. The equilibrium range in the spectrum of wind-generated waves. J Fluid Mech 4, 426-434. doi:10.1017/S0022112058000550.

Pierson, Jr, W.J., Moskowitz, L., 1964. A proposed spectral form for fully developed wind seas based on the similarity theory of S A Kitaigorodskii. J Geophys Res 69, $5181-5190$.

Polton, J.A., 2009. A wave averaged energy equation: Comment on global estimates of wind energy input to subinertial motions in the ekman-stokes layer by bin liu, kejian wu and changlong guan. Journal of oceanography 65, 665-668.

Polton, J.A., Lewis, D.M., Belcher, S.E., 2005. The role of wave-induced coriolisstokes forcing on the wind-driven mixed layer. Journal of Physical Oceanography $35,444-457$.

Powell, M.D., Vickery, P.J., Reinhold, T.A., 2003. Reduced drag coefficient for high wind speeds in tropical cyclones. Nature 422, 279-283.

Qiao, F., Yuan, Y., Yang, Y., Zheng, Q., Xia, C., Ma, J., 2004. Wave-induced mixing in the upper ocean: Distribution and application to a global ocean circulation model. Geophysical Research Letters 31. 
Reichl, B.G., Wang, D., Hara, T., Ginis, I., Kukulka, T., 2016. Langmuir turbulence parameterization in tropical cyclone conditions. Journal of Physical Oceanography 46, 863-886.

Rutgersson, A., Smedman, A.S., Högström, U., 2001. Use of conventional stability parameters during swell. Journal of Geophysical Research: Oceans 106, 2711727134.

Saetra, Ø., Albretsen, J., Janssen, P.A., 2007. Sea-state-dependent momentum fluxes for ocean modeling. Journal of Physical Oceanography 37, 2714-2725.

Sheldon, L., Czaja, A., 2014. Seasonal and interannual variability of an index of deep atmospheric convection over western boundary currents. Q J R Meteorol Soc 140, 22-30. doi: $10.1002 / q j .2103$.

Smyth, W.D., Skyllingstad, E.D., Crawford, G.B., Wijesekera, H., 2002. Nonlocal fluxes and stokes drift effects in the k-profile parameterization. Ocean Dynamics 52, $104-115$.

Sproson, D., Sahlée, E., 2014. Modelling the impact of baltic sea upwelling on the atmospheric boundary layer. Tellus A: Dynamic Meteorology and Oceanography $66,24041$.

Staneva, J., Alari, V., Breivik, Ø., Bidlot, J.R., Mogensen, K., 2017. Effects of waveinduced forcing on a circulation model of the north sea. Ocean Dynamics 67, 81101.

Stokes, G.G., 1847. On the theory of oscillatory waves. Trans Cambridge Philos Soc $8,441-473$.

Sullivan, P.P., McWilliams, J.C., 2010. Dynamics of winds and currents coupled to surface waves. Annual Review of Fluid Mechanics 42.

Sullivan, P.P., McWILLIAMS, J.C., Melville, W.K., 2004. The oceanic boundary layer driven by wave breaking with stochastic variability. part 1. direct numerical simulations. Journal of Fluid Mechanics 507, 143-174. 
Suzuki, N., Fox-Kemper, B., 2016. Understanding stokes forces in the wave-averaged equations. Journal of Geophysical Research: Oceans 121, 3579-3596.

Takaya, Y., Bidlot, J.R., Beljaars, A., Janssen, P., 2010. Refinements to a prognostic प

Terray, E., Donelan, M., Agrawal, Y., Drennan, W., Kahma, K., Williams, A., Hwang, P., Kitaigorodskii, S., 1996. Estimates of kinetic energy dissipation under breaking waves. Journal of Physical Oceanography 26, 792-807.

Thomson, J., Schwendeman, M.S., Zippel, S.F., Moghimi, S., Gemmrich, J., Rogers, W.E., 2016. Wave-breaking turbulence in the ocean surface layer. Journal of Physical Oceanography 46, 1857-1870.

Umlauf, L., Burchard, H., 2003. A generic length-scale equation for geophysical turbulence models. J Mar Res 61, 235-265. doi:10.1357/002224003322005087.

Umlauf, L., Burchard, H., 2005. Second-order turbulence closure models for geophysical boundary layers. A review of recent work. Cont Shelf Res 25, 795-827. doi $10.1016 / j . \operatorname{csr} .2004 .08 .004$.

Van Roekel, L.P., Fox-Kemper, B., Sullivan, P.P., Hamlington, P.E., Haney, S.R., 2012.

The form and orientation of Langmuir cells for misaligned winds and waves. J Geophys Res: Oceans 117, 22, C05001. doi:10.1029/2011JC007516

Veron, F., Melville, W.K., Lenain, L., 2008. Wave-coherent air-sea heat flux. Journal of Physical Oceanography 38, 788-802. 
Wahle, K., Staneva, J., Koch, W., Fenoglio-Marc, L., Ho-Hagemann, H.T., Stanev, E.V., 2017. An atmosphere-wave regional coupled model: improving predictions of wave heights and surface winds in the southern north sea. Ocean Science 13, 289.

WAMDI, 1988. The wam modela third generation ocean wave prediction model. Journal of Physical Oceanography 18, 1775-1810.

Wang, J., Shen, Y., 2011. Development and validation of a three-dimensional, wavecurrent coupled model on unstructured meshes. Science China Physics, Mechanics and Astronomy 54, 42-58.

Wu, L., Rutgersson, A., Nilsson, E., 2017. Atmospheric boundary layer turbulence closure scheme for wind-following swell conditions. Journal of the Atmospheric Sciences 74, 2363-2382.

Wu, L., Rutgersson, A., Sahlée, E., 2015. Upper-ocean mixing due to surface gravity waves. Journal of Geophysical Research: Oceans 120, 8210-8228.

Wu, L., Rutgersson, A., Sahlée, E., Guo Larsén, X., 2016. Swell impact on wind stress and atmospheric mixing in a regional coupled atmosphere-wave model. Journal of Geophysical Research: Oceans 121, 4633-4648.

Table 1: Experiment design.

\begin{tabular}{ll}
\hline Experiments & Group \\
\hline CTL & Control simulation, without wave model \\
STCOR & CTL + Stokes-Coriolis forcing \\
STFUL & STCOR + Stokes drift impact on tracer and mass advection \\
FULL & STFUL + sea-state-dependent momentum and energy fluxes \\
\hline
\end{tabular}



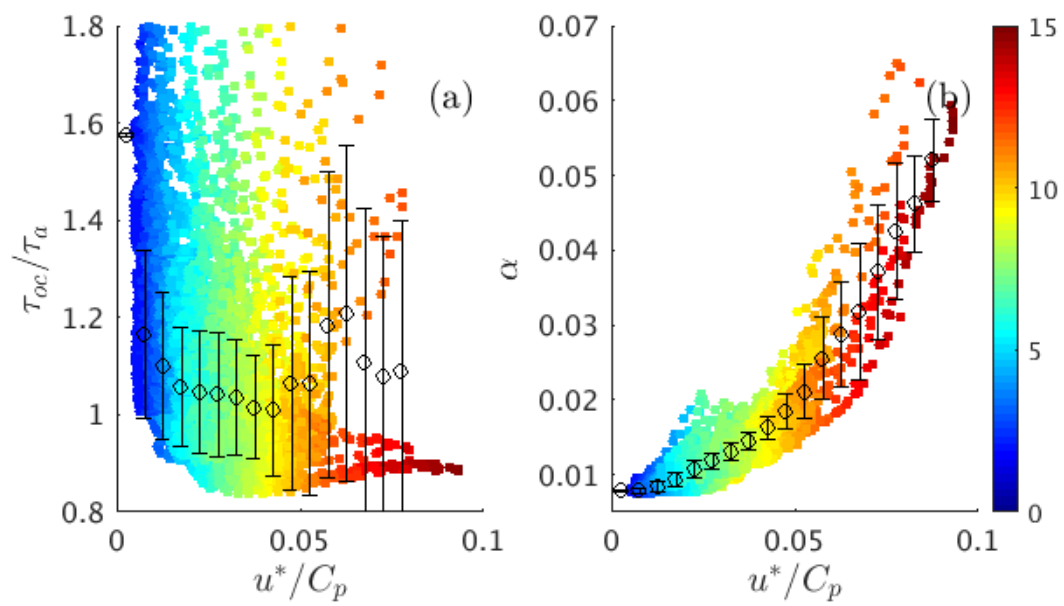

Figure 1: The relationship between $u^{*} / C_{\mathrm{p}}$ and the normalised wind stress $\tau_{\mathrm{oc}} / \tau_{\mathrm{a}}$ (a), and the Charnock coefficient $\alpha$ (b). The color scale represents $U_{10}\left[\mathrm{~m} \mathrm{~s}^{-1}\right]$. The data are from the hourly output data from wave model simulation during December 7th, 2015 in the blue box domain shown in Fig. 2 The circles show the bin average with standard deviation shown as bars. The vertical axis is limited for legibility as only a few data points exceed 1.8 .

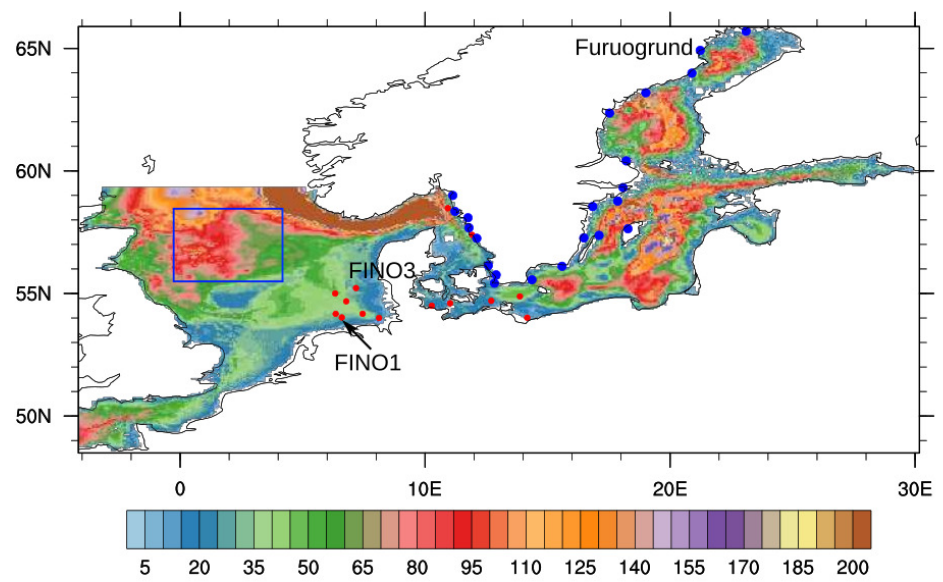

Figure 2: Topography of the model domain and the buoy locations used in this study [m]. The red circles represent temperature measurement stations and the blue dots represent sea level stations used in this study. The blue box represents the area in which data are used in Fig. 18 and 1 


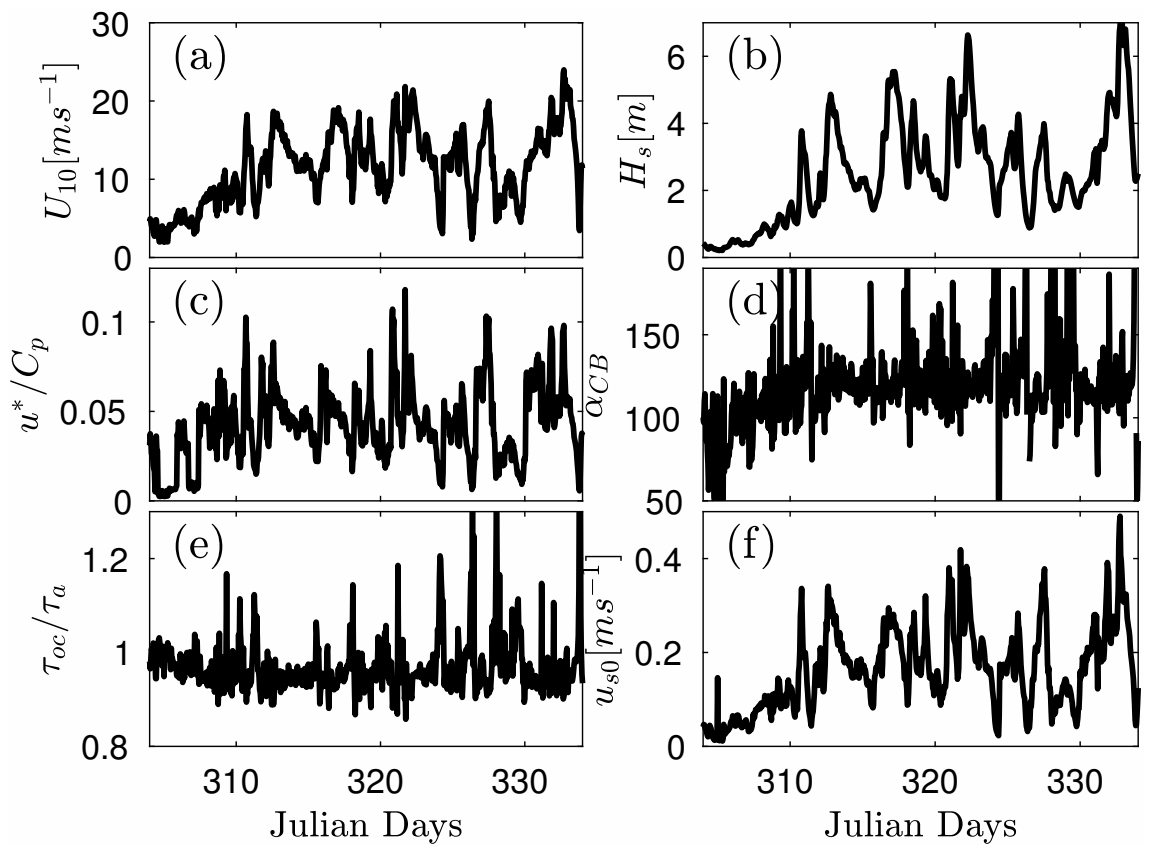

Figure 3: The time series of the mean wind speed $U_{10}$ (a), (b) the significant wave height, (c) inverse wave age $u^{*} / C_{\mathrm{p}}$, (d) $\alpha_{\mathrm{CB}}$, (e) $\tau_{\mathrm{oc}} / \tau_{\mathrm{a}}$ and the surface Stokes drift $u_{\mathrm{s}_{0}}$ at the FINO1 station during the storm simulation period. The wind and wave data are from DWD. 

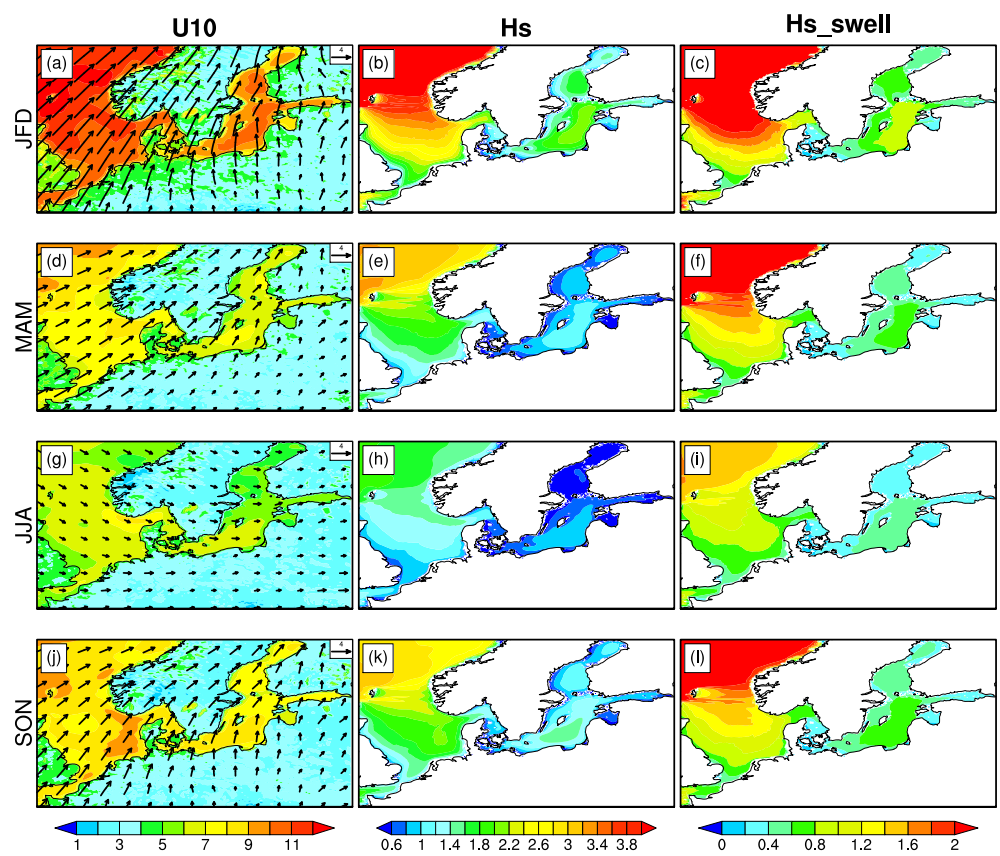

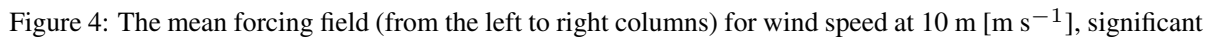
wave height $[\mathrm{m}]$, and the swell significant wave height $[\mathrm{m}]$. The four rows show the mean value in JFD, MAM, JJA, and SON. 


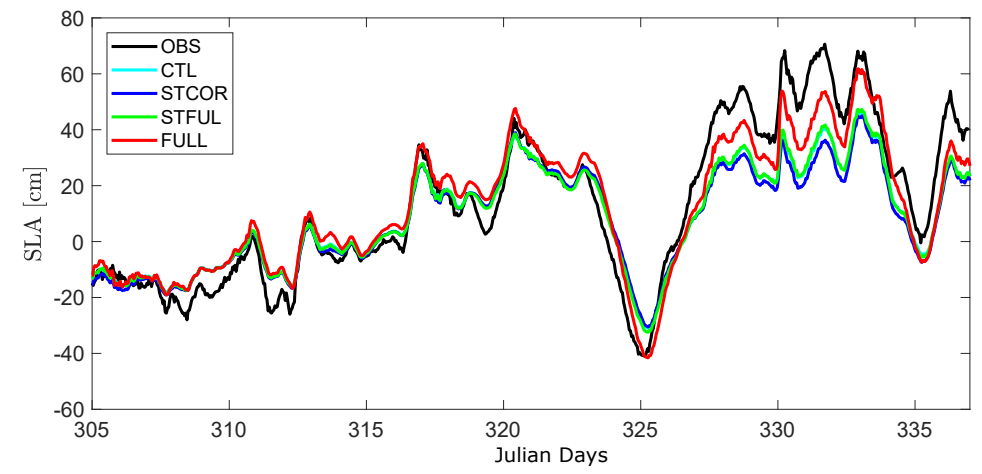

Figure 5: The simulation results of SLA from the four experiments and the measurements during the storm period at station Furuogrund. The lines of STFUL almost overlap CTL.

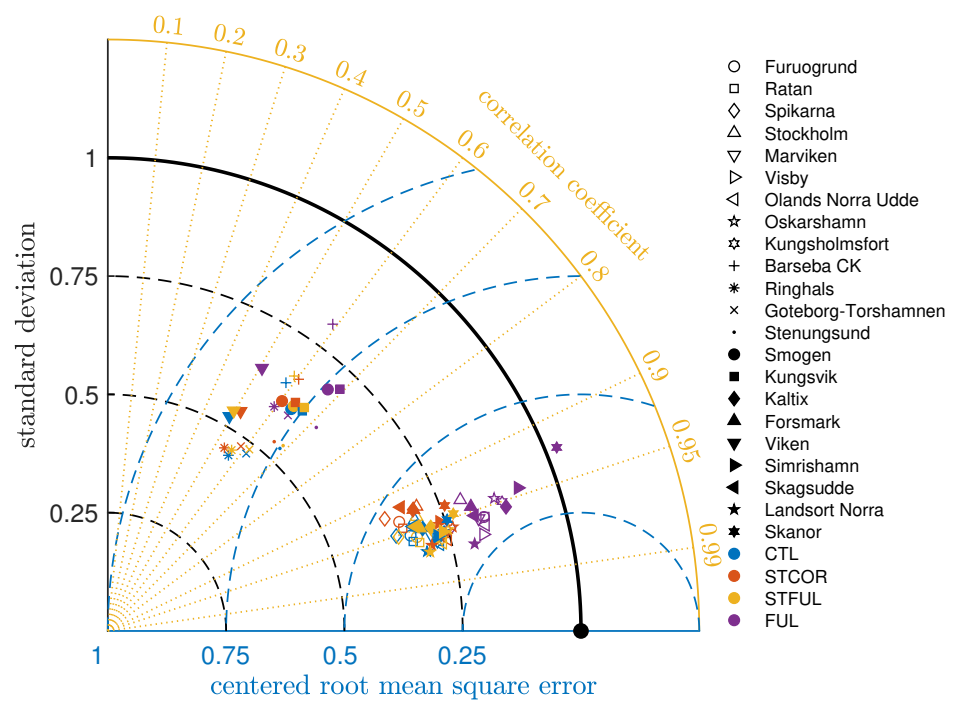

Figure 6: The Taylor diagram of SLA for all stations. 


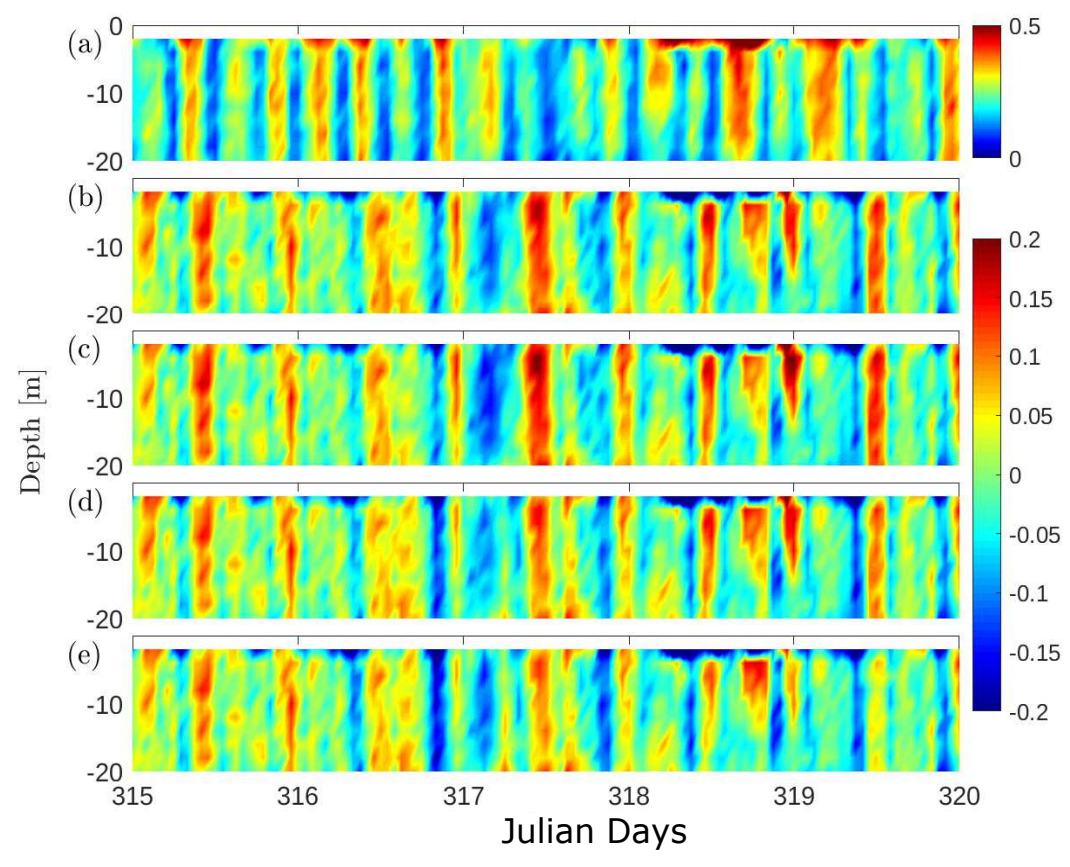

Figure 7: The velocity profiles at FINO3 station for Julian days 315-320 in year 2015: (a) hourly mean measurements (OBS), hourly mean difference CTL-OBS (b), STCOR-OBS (C), STFUL-OBS (d), and FULLOBS (e). 

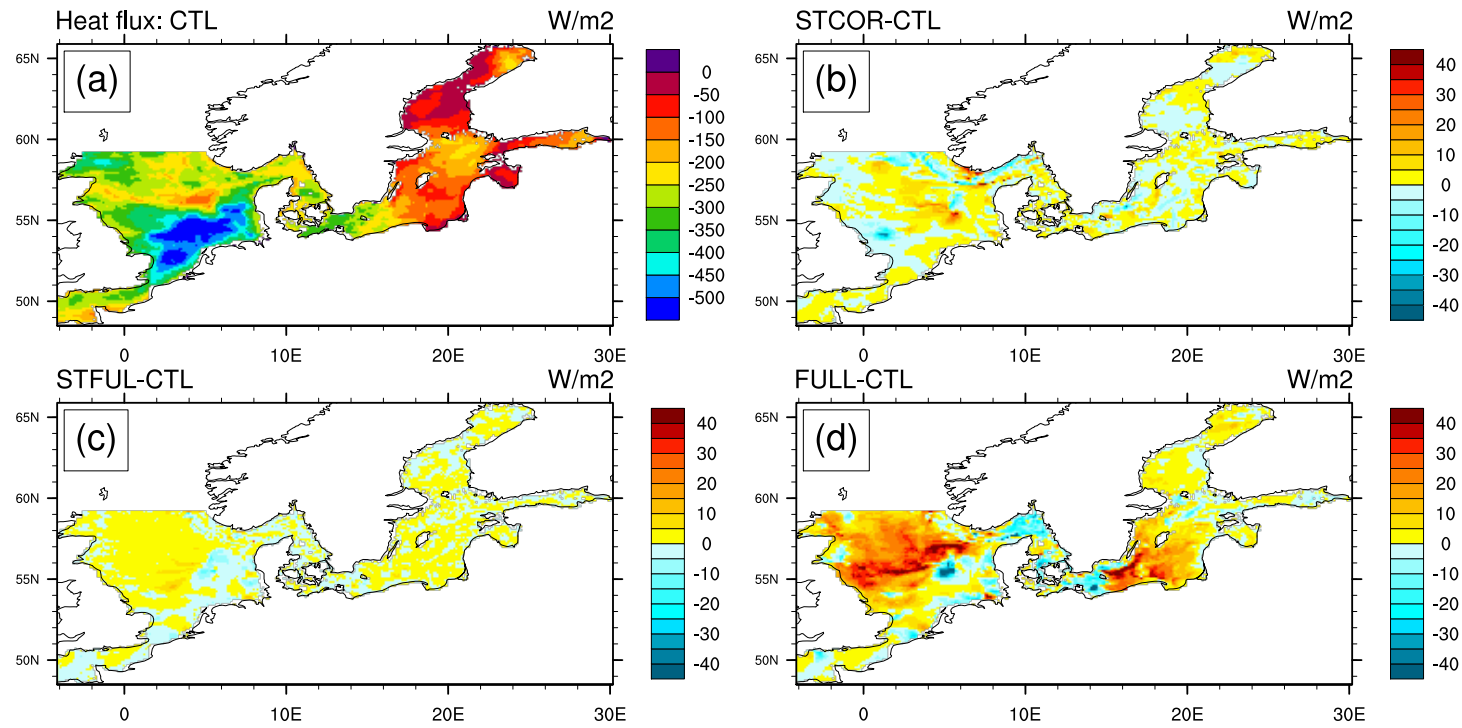

Figure 8: The net heat flux [ $\left[\mathrm{W} \mathrm{m}^{-2}\right.$ ] at 01:00 UTC, Julian day 318 (November 14) for CTL (a), the difference STCOR-CTL (b), STFUL-CTL (c), and FULL-CTL (d). The negative flux in (a) means heat flux from the ocean to the atmosphere. The positive flux in (b)-(d) means that the wave influence reduces the flux from the ocean to the atmosphere. 

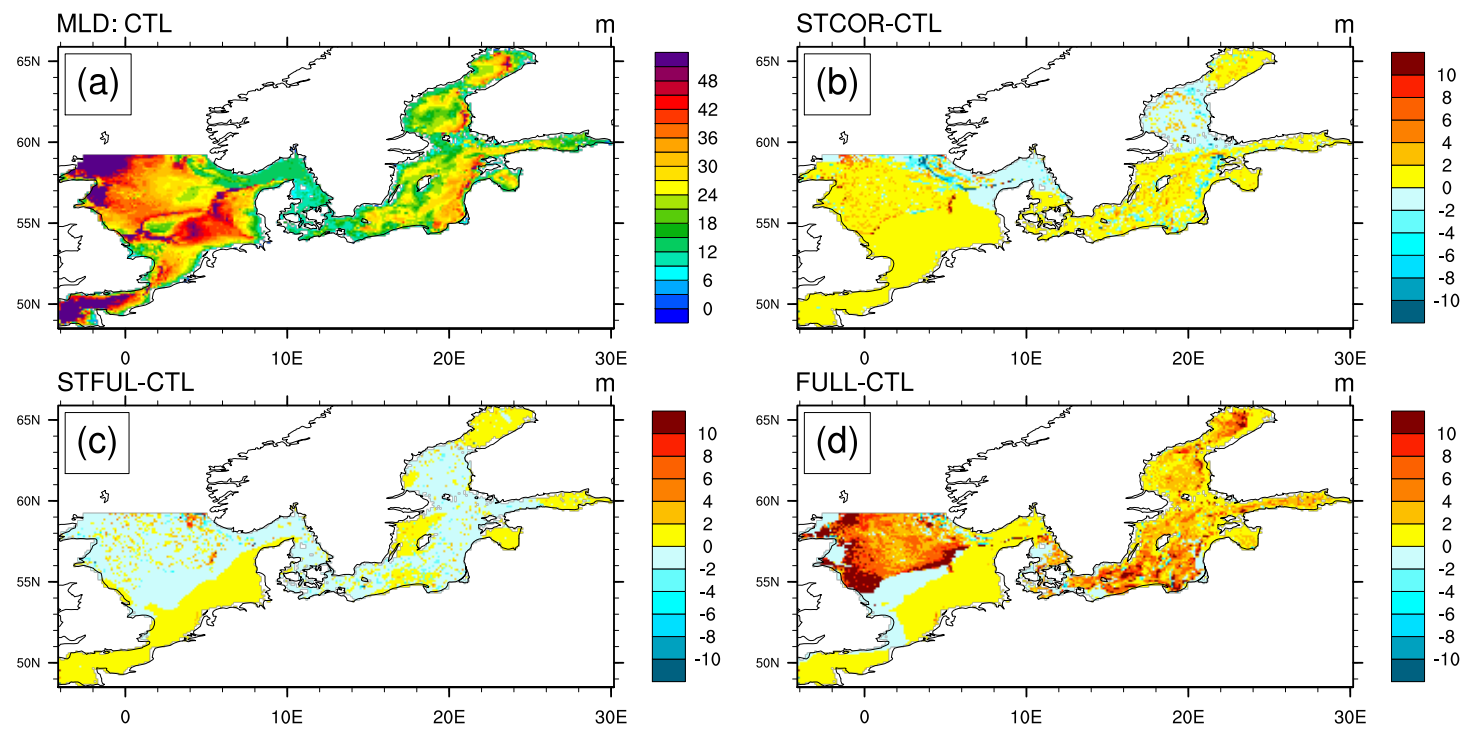

Figure 9: The mixed layer depth [m] at 01:00 UTC, Julian day 318 (November 14) for CTL (a), the difference STCOR-CTL (b), STFUL-CTL (c), and FULL-CTL (d). 

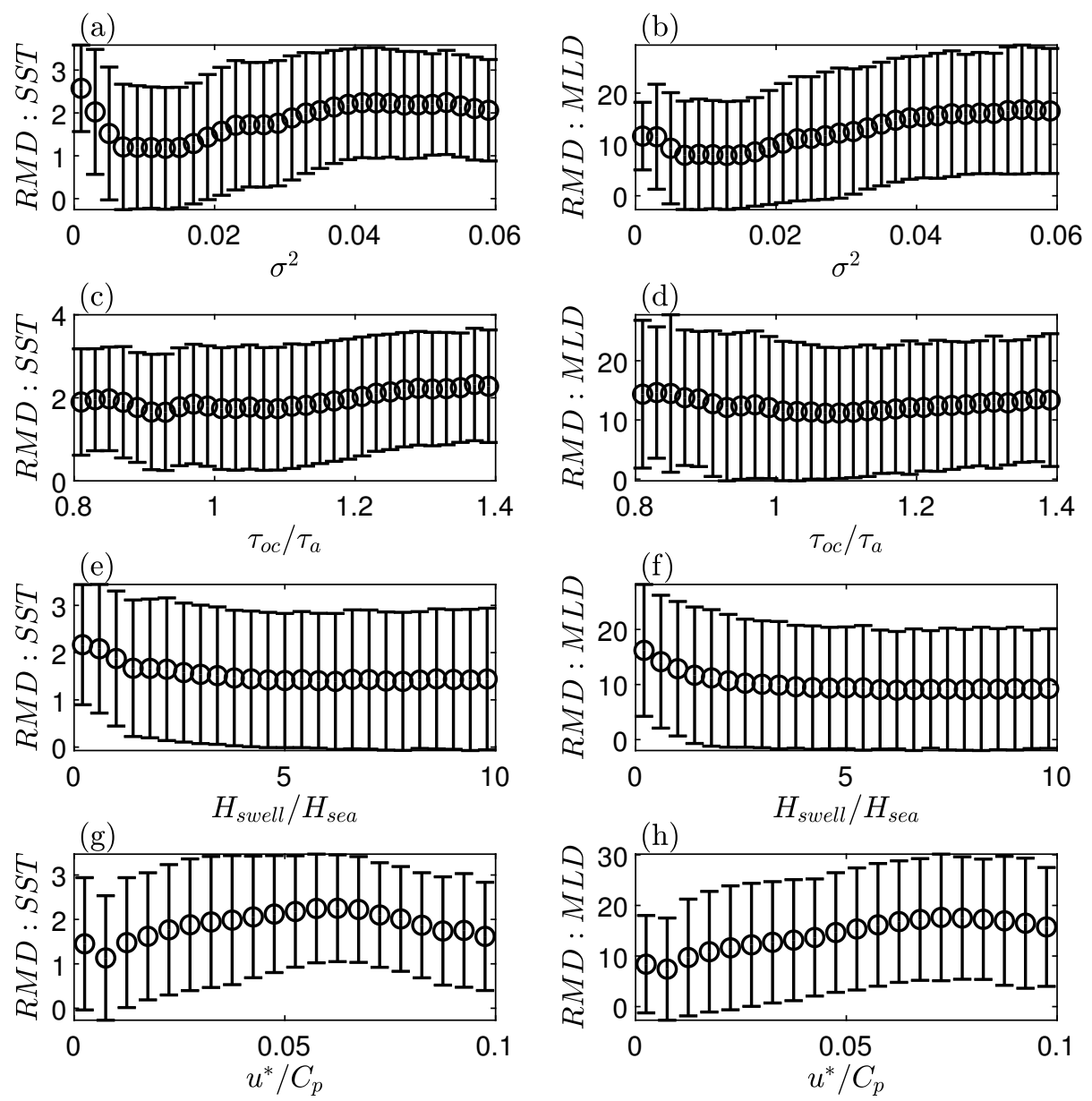

Figure 10: The relative mean difference of SST [\%] under different mean squre wave slope (a), (c) $\tau_{\mathrm{OC}} / \tau_{\mathrm{a}}$, (e) $H_{\text {swell }} / H_{\text {sea }}$, and (g) inverse wave age $u^{*} / C_{\mathrm{p}}$. The relative mean difference of the mixed layer depth under different mean squre wave slope (b), (d) $\tau_{\mathrm{oc}} / \tau_{\mathrm{a}}$, (f) $H_{\text {swell }} / H_{\mathrm{sea}}$, and (h) inverse wave age $u^{*} / C_{\mathrm{p}}$. The data used in this figure are the hourly data from the area shown in blue box in Fig. 2 


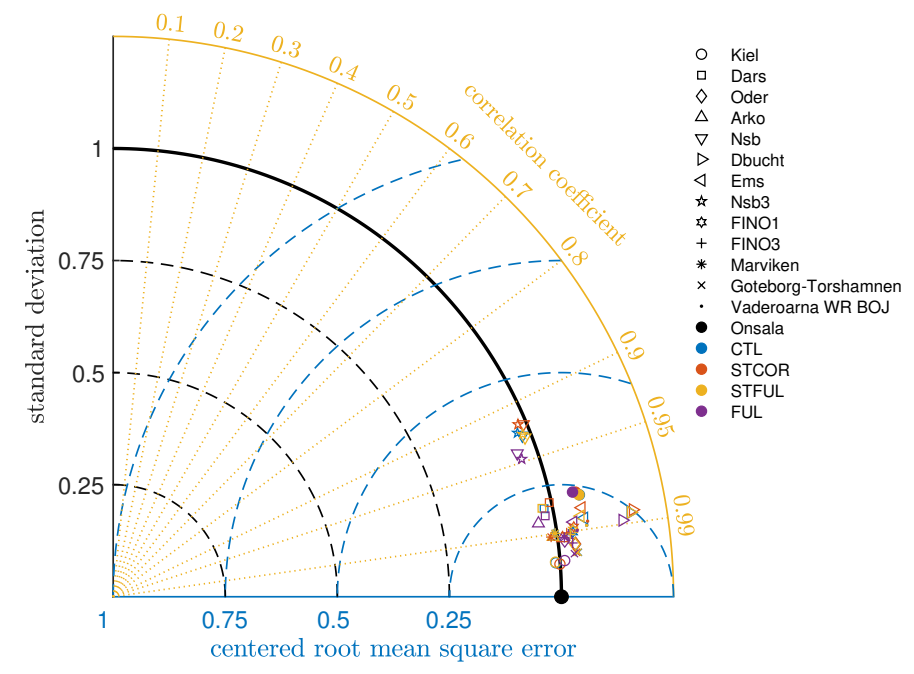

Figure 11: The Taylor diagram of SST for all stations.

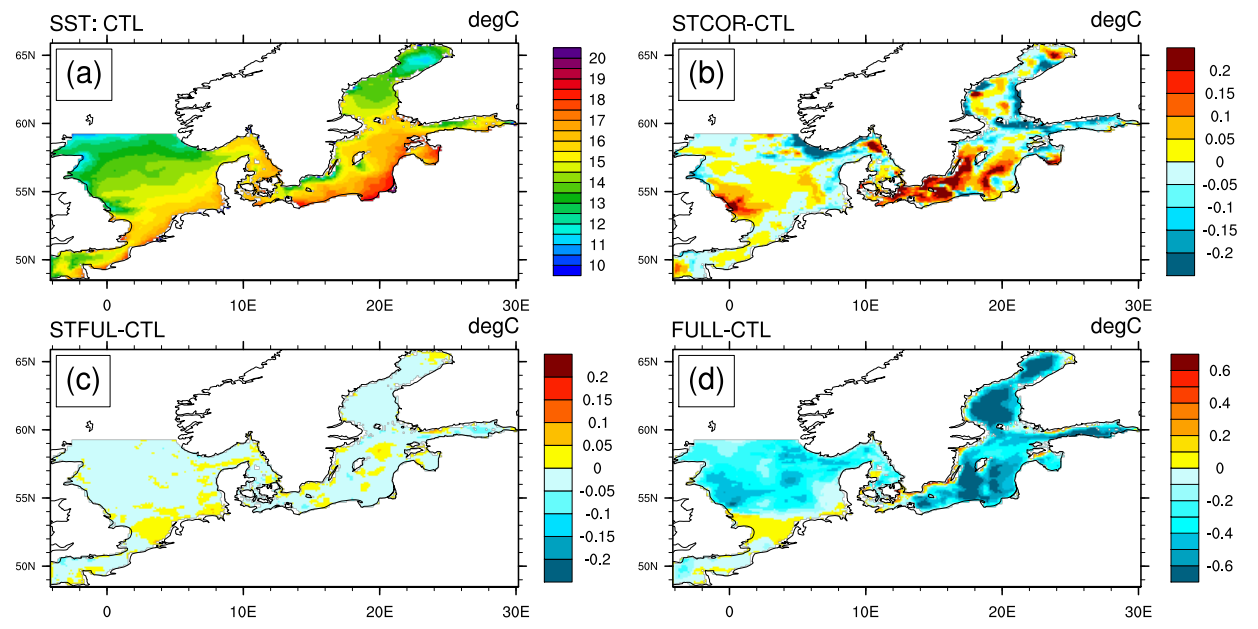

Figure 12: The mean SST $\left[{ }^{\circ} \mathrm{C}\right]$ of June, July and August in 2015 (a), the mean SST difference STCOR-CTL (b), STFUL-CTL (c), and FULL-CTL (d) for the months June, July and August. 

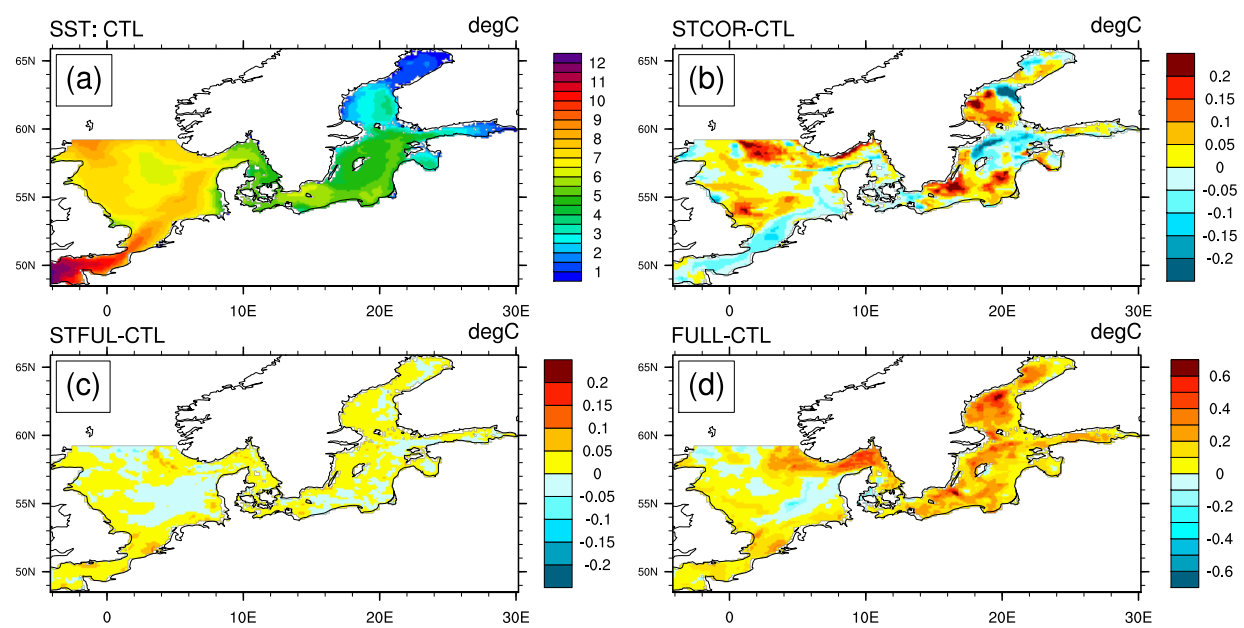

Figure 13: Same as Fig. 12 but for the months December, January and February 2015. 

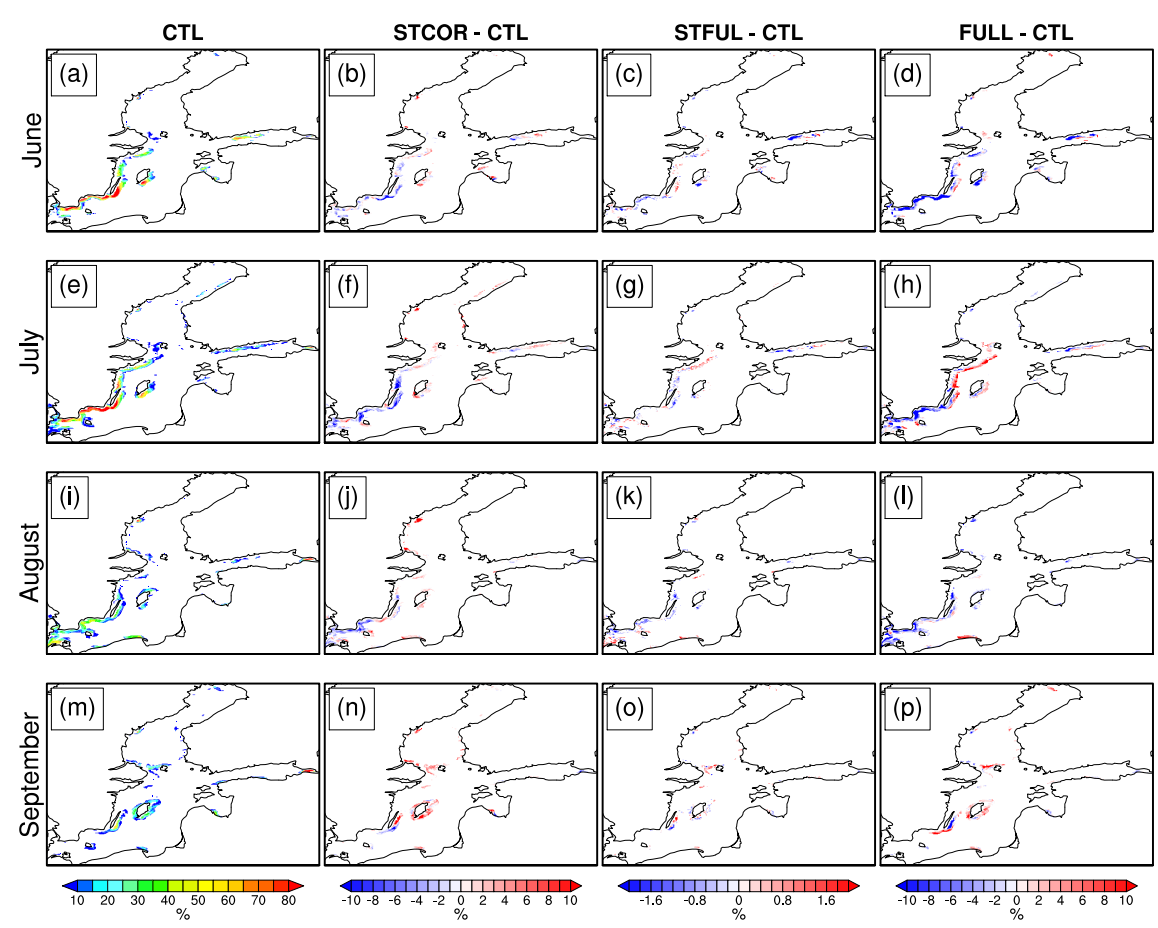

Figure 14: The frequency of upwelling in the control experiment for the months of June, July, August and September, 2015 [\%]. The four columns represent the upwelling frequency in the control experiment, the difference between the experiment STCOR, STFUL, FULL and the control experiments. The four rows represent the months June, July, August and September 2015. The criterion for upwelling are fulfilled when the SST difference from the zonal mean temperature is greater than $2.5^{\circ} \mathrm{C}$. 

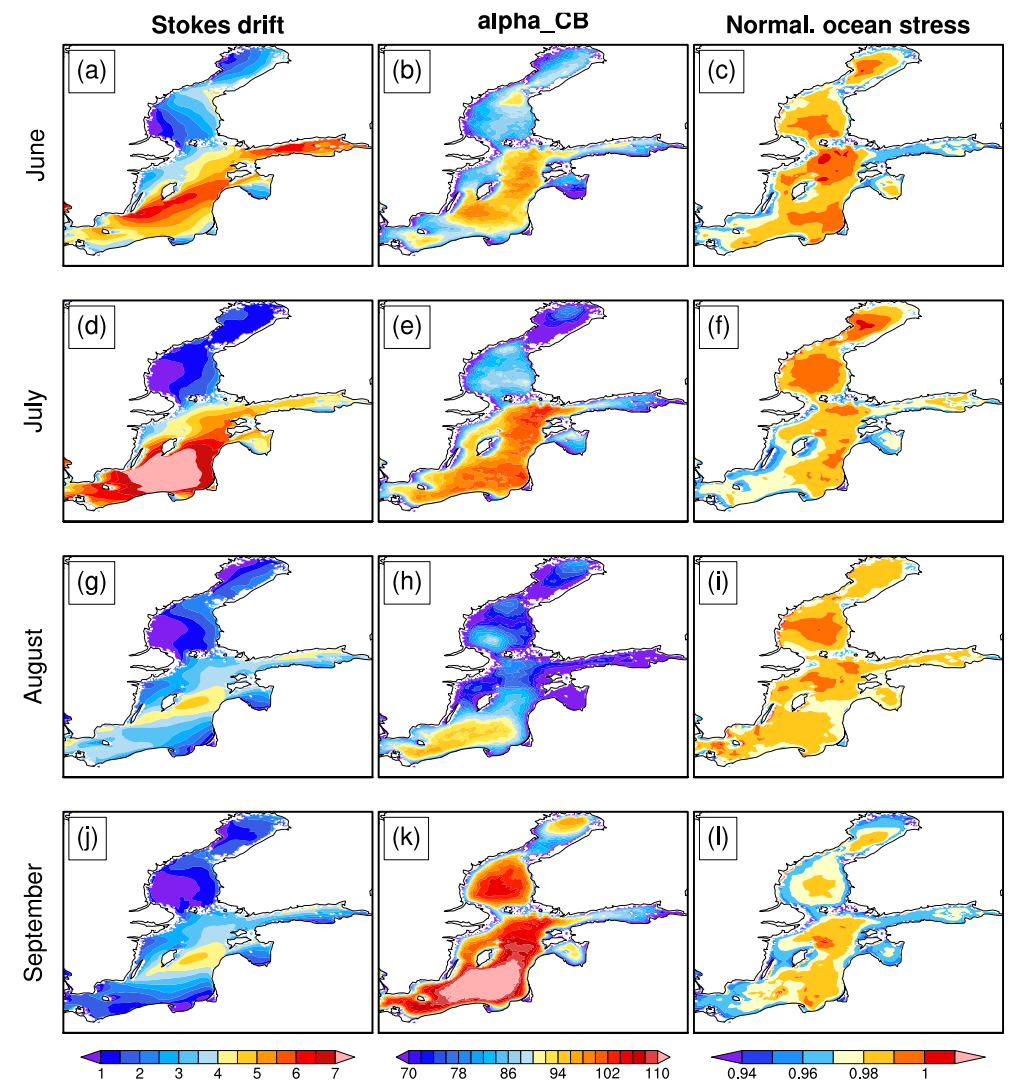

Figure 15: The three columns show the mean surface Stokes drift, the wave energy coefficient $\alpha_{C B}$, and the normalized ocean stress $\tau_{\mathrm{oc}} / \tau_{\mathrm{a}}$. The four rows are data for June, July, August, and September 2015. 


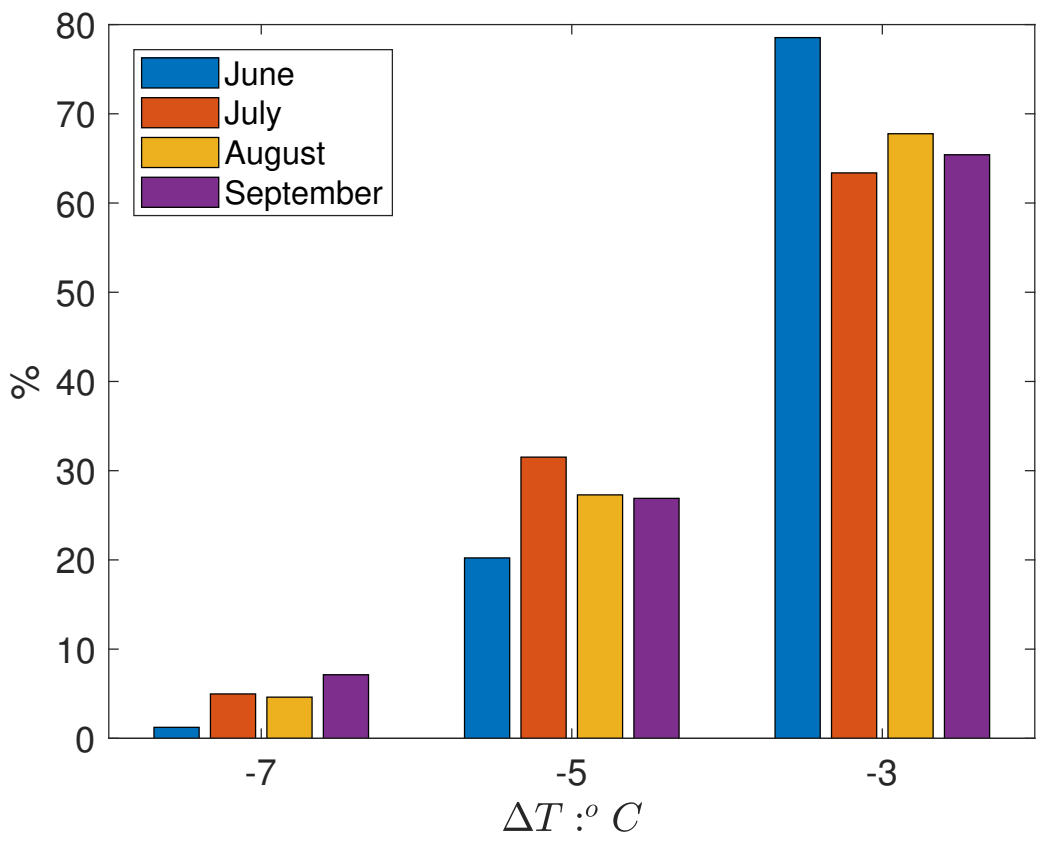

Figure 16: The normalized distribution of the upwelling intensity (with $2{ }^{\circ} \mathrm{C}$ bins) in June, July, August and September 2015. 

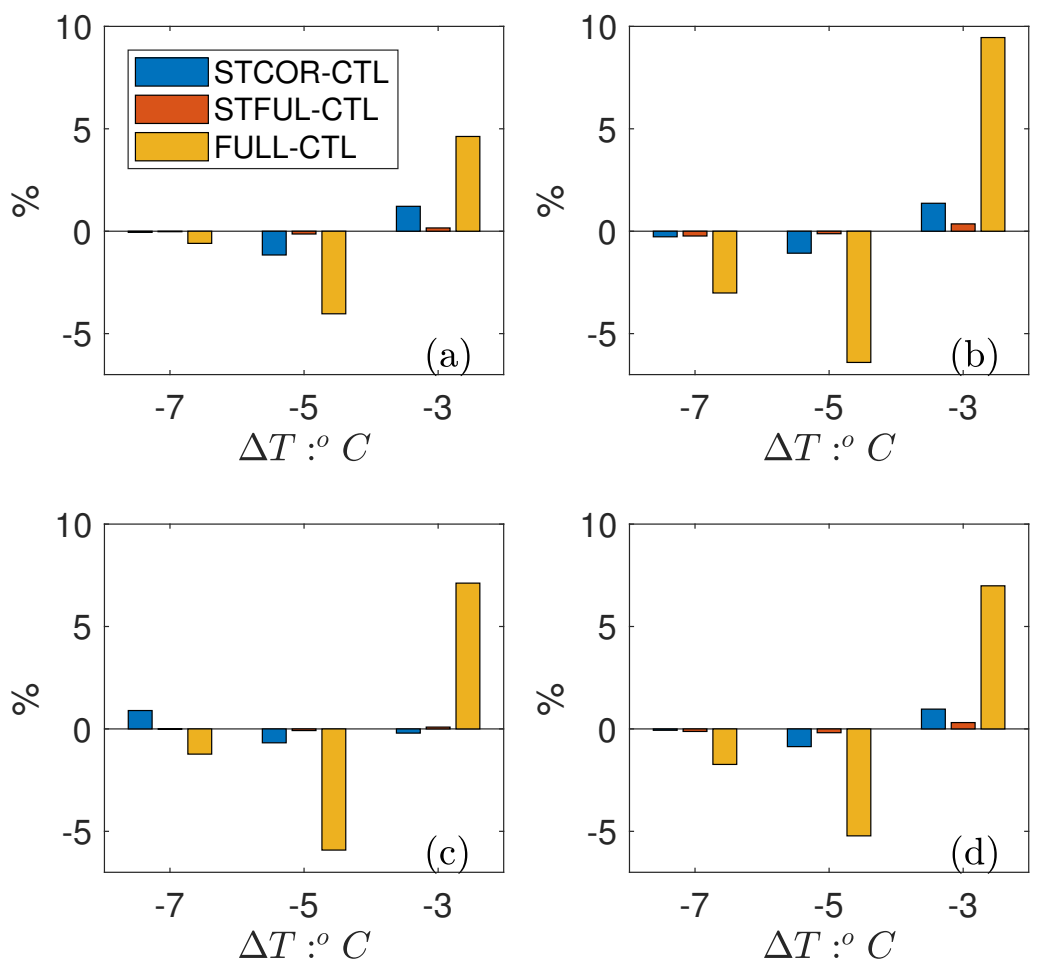

Figure 17: The wave effect on the distribution of the upwelling intensity in (a) June, (b) July, (c) August, and (d) September 2015. 
Table 2: The location of the stations shown in Fig. 2

\begin{tabular}{|c|c|c|c|c|c|}
\hline SLA Station & Lat & Lon & SST Station & Lat & Lon \\
\hline Furuogrund & 64.92 & 21.23 & Kiel & 54.50 & 10.27 \\
\hline Ratan & 63.99 & 20.89 & Dars & 54.70 & 12.70 \\
\hline Spikarna & 62.36 & 17.53 & Oder & 54.01 & 14.17 \\
\hline Stockholm & 59.32 & 18.08 & Arko & 54.88 & 13.87 \\
\hline Marviken & 58.55 & 16.84 & Nsb & 55.00 & 6.33 \\
\hline Visby & 57.64 & 18.28 & Dbucht & 55.17 & 7.45 \\
\hline Olands Norra Udde & 57.37 & 17.10 & Ems & 54.17 & 6.35 \\
\hline Oskarshamn & 57.27 & 16.48 & Nsb3 & 54.68 & 6.78 \\
\hline Kungsholmsfort & 56.11 & 15.59 & FINO1 & 54.02 & 6.60 \\
\hline Barseba CK & 55.76 & 12.90 & FINO3 & 55.22 & 7.18 \\
\hline Ringhals & 57.25 & 12.11 & Marviken & 58.55 & 16.84 \\
\hline Goteborg-Torshamnen & 57.68 & 11.79 & Goteborg-Torshamnen & 57.68 & 11.79 \\
\hline Stenungsund & 58.09 & 11.83 & Vaderoarna WR BOJ & 58.48 & 10.93 \\
\hline Smogen & 58.35 & 11.22 & Onsala & 57.39 & 11.92 \\
\hline Kungsvik & 59.00 & 11.13 & & & \\
\hline Kaltix & 65.70 & 23.10 & & & \\
\hline Forsmark & 60.41 & 18.21 & & & \\
\hline Viken & 56.14 & 12.58 & & & \\
\hline Simrishamn & 55.56 & 14.36 & & & \\
\hline Skagsudde & 63.19 & 19.01 & & & \\
\hline Landsort Norra & 58.77 & 17.86 & & & \\
\hline Skanor & 55.42 & 12.83 & & & \\
\hline
\end{tabular}



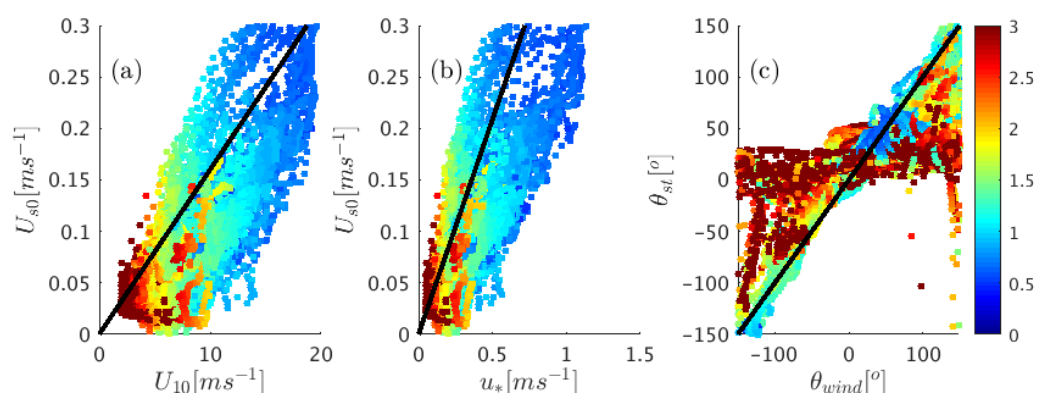

Figure 18: The relationship between $U_{10}$ and the magnitude of the surface Stokes drift is shown in (a) and the black line represents the $u_{\mathrm{s}_{0}}=0.016 U_{10}$ Li and Garrett 1993). Panel (b) shows the relationship between the $u_{*}$ and the magnitude of the surface Stokes drift, and the black line shows $u_{\mathrm{s}_{0}}=0.377\left|\tau / \rho_{\mathrm{w}}\right|^{1 / 2}$ (Madec et al. 2015). Panel (c) shows the surface Stokes drift direction and the direction of $U_{10}$. Here the black line represents the 1:1 line. The color represents the wave age, $C_{\mathrm{p}} / U_{10}$. The data are from the hourly output data from wave model simulation during Julian day 341 (December 7th), 2015 in the blue box domain shown in Fig. 2 